\title{
Loss of the Tectorial Membrane Protein CEACAM16 Enhances Spontaneous, Stimulus-Frequency, and Transiently Evoked Otoacoustic Emissions
}

\author{
Mary Ann Cheatham, ${ }^{1}$ Richard J. Goodyear, ${ }^{3}$ Kazuaki Homma, ${ }^{4}$ P. Kevin Legan, ${ }^{3}$ Julia Korchagina, ${ }^{3}$ Souvik Naskar, ${ }^{3}$ \\ Jonathan H. Siegel, ${ }^{1}$ DPeter Dallos, ${ }^{1,2}$ Jing Zheng, ${ }^{4}$ and Guy P. Richardson ${ }^{3}$ \\ ${ }^{1}$ Roxelyn and Richard Pepper Department of Communication Sciences and Disorders, The Knowles Hearing Center, and ${ }^{2}$ Department of Neurobiology, \\ Northwestern University, Evanston, Illinois 60208, ${ }^{3}$ Sussex Neuroscience, School of Life Sciences, University of Sussex, Falmer, Brighton, BN1 9QG, United \\ Kingdom, and ${ }^{4}$ Department of Otolaryngology-Head and Neck Surgery, The Knowles Hearing Center, Feinberg School of Medicine, Northwestern \\ University, Chicago, Illinois 60611
}

$\alpha$-Tectorin (TECTA), $\beta$-tectorin (TECTB), and carcinoembryonic antigen-related cell adhesion molecule 16 (CEACAM) are secreted glycoproteins that are present in the tectorial membrane (TM), an extracellular structure overlying the hearing organ of the inner ear, the organ of Corti. Previous studies have shown that TECTA and TECTB are both required for formation of the striated-sheet matrix within which collagen fibrils of the TM are imbedded and that CEACAM16 interacts with TECTA. To learn more about the structural and functional significance of CEACAM16, we created a Ceacam16-null mutant mouse. In the absence of CEACAM16, TECTB levels are reduced, a clearly defined striated-sheet matrix does not develop, and Hensen's stripe, a prominent feature in the basal two-thirds of the TM in WT mice, is absent. CEACAM16 is also shown to interact with TECTB, indicating that it may stabilize interactions between TECTA and TECTB. Although brain-stem evoked responses and distortion product otoacoustic emissions are, for most frequencies, normal in young mice lacking CEACAM16, stimulus-frequency and transiently evoked emissions are larger. We also observed spontaneous otoacoustic emissions (SOAEs) in $70 \%$ of the homozygous mice. This incidence is remarkable considering that $<3 \%$ of WT controls have SOAEs. The predominance of SOAEs $>15 \mathrm{kHz}$ correlates with the loss of Hensen's stripe. Results from mice lacking CEACAM16 are consistent with the idea that the organ of Corti evolved to maximize the gain of the cochlear amplifier while preventing large oscillations. Changes in TM structure appear to influence the balance between energy generation and dissipation such that the system becomes unstable.

Key words: CEACAM16; cochlea; Hensen's stripe; mouse; otoacoustic emissions; tectorial membrane

\section{Introduction}

The carcinoembryonic antigen-related cell adhesion molecule (CEACAM) family of proteins contains 22 members thought to be involved in cell-to-cell interactions (Zid and Drouin, 2013). The secreted glycoprotein CEACAM16 is present in the cochlea, where it is observed in supporting cells, interdental cells of the

\footnotetext{
Received March 28, 2014; revised May 29, 2014; accepted June 11, 2014

Author contributions: M.A.C., J.H.S., and G.P.R. designed research;M.A.C., R.J.G., K.H., P.K.L., J.K., S.N., and G.P.R. performed research; J.Z. contributed unpublished reagents/analytic tools; M.A.C., R.J.G., K.H., P.K.L., and G.P.R. analyzed data; M.A.C., P.D., and G.P.R. wrote the paper.

This work was supported by the National Institute on Deafness and Other Communication Disorders, National Institutes of Health (Grant DC000089 to M.A.C. and Grant DC011813 to J.Z.) and The Wellcome Trust (Grant 087377 to G.P.R.). J.K. was supported by a doctoral studentship from Action on Hearing Loss. We thank Roxanne Edge, Elyssa Katz, Ted Kim, Yingjie Zhou, Lindsey Welstead, and Lynda Penfold for help with data collection and colony management.

The authors declare no competing financial interests.

Correspondence should be addressed to either of the following: Mary Ann Cheatham, 2-240 Frances Searle Bldg., 2240 Campus Drive, Northwestern University, Evanston IL 60208, E-mail: m-cheatham@northwestern.edu; or Guy P. Richardson, Sussex Neuroscience, School of Life Sciences, University of Sussex, Falmer, Brighton, BN1 9QG, UK, E-mail: g.p.richardson@sussex.ac.uk.

DOI:10.1523/JNEUROSCI.1256-14.2014

Copyright $\odot 2014$ the authors $\quad 0270-6474 / 14 / 3410325-14 \$ 15.00 / 0$
}

limbus, and, principally, in the tectorial membrane (TM), an accessory structure overlying the organ of Corti (Zheng et al., 2011; Kammerer et al., 2012). We showed recently (Zheng et al., 2011) that the Ceacam16 gene is mutated in American Family 1070 , a family with a hearing loss that begins in adolescence and progresses with age to an $\sim 50 \mathrm{~dB}$ threshold shift, a decrease in sensitivity consistent with a loss of cochlear amplification (Chen et al., 1995). These individuals do not have a mutation in myosin heavy-chain 14 nonmuscle (MYH14), unlike other individuals classified as having nonsyndromic autosomal dominant hearing loss DFNA4 (Yang et al., 2005). Instead, a missense mutation (c.481 >C, p.T140P) is present in the gene encoding CEACAM16 that is predicted to disrupt a glycosylation site and interfere with protein stability (Zheng et al., 2011). Individuals with mutations in MYH14 are now designated DFNA4A and those with a mutation in Ceacam16 are DFNA4B.

The TM is an acellular structure that contains collagens (Thalmann et al., 1986; Richardson et al., 1987) and several noncollagenous proteins, including $\alpha$-tectorin (TECTA) and $\beta$-tectorin (TECTB) (Legan et al., 1997), CEACAM16 (Zheng et al., 2011), otogelin (Cohen-Salmon et al., 1997), otogelin-like (Yariz et al., 
2012), and otolin (Deans et al., 2010). Two additional proteins may mediate attachment of the TM to the cochlear epithelium: otoancorin on the surface of the limbus (Lukashkin et al., 2012) and stereocilin at the tips of the outer hair cell (OHC) stereocilia (Verpy et al., 2011). Of the noncollagenous proteins, TECTA and TECTB dominate the proteinaceous content, but their mRNA is not expressed after about postnatal day 22 (P22; Rau et al., 1999), making it difficult to conceive how the TM is maintained throughout life. In contrast, Ceacam16 mRNA expression is observed by $\mathrm{P} 10$ and the protein is distributed throughout the TM by P18 (Kammerer et al., 2012). Ceacam16 mRNA expression is maintained in older animals (Kammerer et al., 2012), and the continuous production of CEACAM16 may stabilize TECTA in the TM of adults because the two proteins are known to interact (Zheng et al., 2011).

Transgenic mouse models with mutations in Tecta and Tectb, as well as long-standing theoretical considerations (Békésy, 1960), indicate that the TM is essential for normal hearing (Richardson et al., 2008; Richardson et al., 2011). When Tecta is mutated (Legan et al., 2000; Legan et al., 2005; Legan et al., 2014), threshold shifts and changes in tuning are observed. Because of the close association between TECTA and CEACAM16, we investigated anatomical and physiological changes in mice lacking CEACAM16. Loss of CEACAM16 alters TM structure and enhances certain types of otoacoustic emissions that can be recorded in the ear canal and reflect $\mathrm{OHC}$ activity. In young mice, these alterations occur without significant changes in cochlear output.

\section{Materials and Methods}

Creation of the Ceacam16-null mutant mouse. The mouse strain used for this project was created from an ES cell clone obtained from the National Center for Research Resources-National Institutes of Health (NIH)supported Knockout Mouse Project (KOMP) Repository (www.komp. org) and generated by the CSD (CHORI, Sanger Institute, and UC Davis) consortium for the NIH-funded KOMP. In ES cell line EPD0319_6_B07, a splice acceptor site, followed by a lacZ expression cassette encoding $\beta$-galactosidase (Testa et al., 2004), is inserted into intron 1 of Ceacam16 to create the Ceacam16-null allele, Ceacam16 ${ }^{\mathrm{tm} 1(\mathrm{KOMP}) \mathrm{Wtsi}}$, in which $\beta$-galactosidase is a reporter of Ceacam 16 gene expression. Chimeras were produced at the University of Sussex by injecting the ES cells into C57BL/6BrdCrHsd- yyr $^{\mathrm{c}}$ (Charles River Laboratories) 3.5-d-old blastocysts and transferring into $2.5 \mathrm{~d}$ pseudopregnant C57BL/6J $\times$ CBA/Ca F1 hybrid females using standard methods (Papaioannou and Johnson, 1993). The parental ES cell line, JM8A1.N3, is C57BL/6N-A ${ }^{\mathrm{tm} 1 \mathrm{Brd}}$ and the heterozygous $\mathrm{A}^{\mathrm{tm} 1 \mathrm{Brd}}$ allele confers an agouti coat color in chimeras (Pettitt et al., 2009). Chimeric mice (6-8 weeks of age) were test mated with $\mathrm{C} 57 \mathrm{BL} / 6 \mathrm{~N}-\mathrm{A}^{\text {tm1Brd }}$ females. Tail snips were taken from pups at 3 weeks of age to identify germline transmission by PCR. One germline transmitting chimera was bred to C57BL/6J (Harlan Laboratories) mice to establish the line Ceacam $16^{\mathrm{tm} 1(\mathrm{KOMP}) \mathrm{Wtsi}}$. The auditory sensitivity of the C57BL/6J and C57BL/6N strains is the same (Kane et al., 2012). Herein, the Ceacam $16^{\mathrm{tm1} \text { (KOMP)Wtsi }}$ allele is referred to as Ceacam $16^{\beta \text { gal }}$.

Sperm from homozygous Ceacam $16^{\beta \mathrm{gal} /} \beta \mathrm{gal}$ mutants was cryopreserved (Ostermeier et al., 2008) and rederived on a C57BL/6J (Jackson Laboratories) background at Northwestern University's Transgenic and Targeted Mutagenesis Laboratory (TTML). Data were acquired from mice between 3 and 7 weeks of age. Although subjects were obtained using both heterotypic and homotypic breeding, most of the null mutant data were obtained from the latter.

Genotyping. Tail snips were either used directly for PCR (Malumbres et al., 1997) or genomic DNA was purified from tail samples using genomic DNA purification kits obtained from either Promega or Sigma-Aldrich. Standard PCR was used to genotype mice. The PCR band for the transgene is $308 \mathrm{bp}$ in size and was created using the following primer pair: CeaGen F1, 5' GGG GCA TAC CTA GCA AGA GTA AGG 3' (forward primer), and Lar 3.1, 5' CAC AAC GGG TTC TTC TGT TAG TCC 3' (reverse primer). The PCR band for WT is $266 \mathrm{bp}$ and was created using the following primer pair: CeaGen F2, 5' CAA GGA CCT GCT AGT CTA TGC CTG 3' (forward primer), and CeaGen R2, 5' TCC CAT CCC ACA CTG CTC ACT CAC 3' (reverse primer).

$X$-Gal staining of Ceacam16-driven $\beta$-galactosidase expression. Mouse cochleae were dissected in PBS and transferred to cold X-Gal fixative (1\% formaldehyde, $0.25 \%$ glutaraldehyde, $2 \mathrm{~mm} \mathrm{MgCl}_{2}$, $5 \mathrm{~mm}$ EGTA, $0.02 \%$ $\mathrm{NP}-40$ in $1 \times \mathrm{PBS}$ ) and fixed for $2 \mathrm{~h}$ on ice. After fixation, cochleae were washed $3 \times$ in PBS at room temperature. The bone between the round and oval windows was broken and a small hole was made at the apex. Cochleae were then transferred into $35 \mathrm{~mm}$ Petri dishes, each containing $3 \mathrm{ml}$ of X-Gal solution ( $5 \mathrm{~mm}$ potassium ferricyanide, $5 \mathrm{~mm}$ potassium ferrocyanide, $0.01 \%$ sodium deoxycholate, $0.02 \%$ NP-40, 2 mM $\mathrm{MgCl}_{2}$, $2.5 \mathrm{~mm} \mathrm{X}-\mathrm{Gal}$ in PBS) and stored in the dark at $4^{\circ} \mathrm{C}$ for $5 \mathrm{~d}$, with the X-Gal solution replaced with fresh solution on day 3 . After $5 \mathrm{~d}$, cochleae were washed $3 \times$ in PBS containing $0.02 \%$ NP- 40 , refixed in cold X-Gal fixative for $2 \mathrm{~h}$ on ice, and washed a further $3 \times$ in PBS containing $0.02 \%$ NP-40. Bony cochleae were decalcified in $0.5 \mathrm{M}$ EDTA, $\mathrm{pH} 8.0$, for $2-4 \mathrm{~d}$, depending on the age of the animal, and cryosectioned as described previously (Legan et al., 2014).

Antibody labeling. Cryosections were preblocked for $1 \mathrm{~h}$ in PBS containing $10 \%$ horse serum (PBS/HS) and stained overnight at room temperature in a humid chamber with a 1:200 dilution of mouse anti- $\beta$ galactosidase $\operatorname{IgG}_{2 \mathrm{a}}$ antibody (Promega). Slides were then washed $3 \times$ in PBS and labeled for $2 \mathrm{~h}$ with 1:500 Alexa Fluor 555-conjugated rabbit anti-mouse $\operatorname{IgG}_{2 \mathrm{a}}$ (Invitrogen) and 1:200 FITC phalloidin (Invitrogen) diluted in PBS/HS. Slides were then washed a further $3 \times$ in PBS and mounted in Vectashield (Vector Laboratories). Stained slides were imaged on a Zeiss LSM510 confocal microscope, using a $63 \times, 1.2$ numerical aperture water-immersion lens.

Light and electron microscopy. Mice were killed by a lethal overdose of anesthetic, the cochleae removed, and the oval and round windows opened in PBS. A small hole was made through the bone at the apical end of each cochlea and $20 \mu \mathrm{l}$ of fixative $(2.5 \%$ glutaraldehyde in $0.1 \mathrm{M}$ sodium cacodylate, $\mathrm{pH} 7.2$, containing $1 \%$ tannic acid) was slowly perfused through the oval window, followed by a further $20 \mu \mathrm{l}$ of fixative through the hole made in the apical end. The cochleae were then immersed in fixative for $\sim 4 \mathrm{~h}$ at room temperature, followed by $\sim 12 \mathrm{~h}$ at $4^{\circ} \mathrm{C}$. After 3 washes in $0.1 \mathrm{M}$ sodium cacodylate, $\mathrm{pH} 7.2$, cochleae were postfixed with $1 \%$ osmium tetroxide in $0.1 \mathrm{~m}$ sodium cacodylate, $\mathrm{pH} 7.2$, for $2-4 \mathrm{~h}$ at room temperature. Samples were rotated in $1.5 \mathrm{ml}$ tubes during fixation. After osmication, cochleae were washed $3 \times$ in $0.1 \mathrm{M}$ sodium cacodylate and then decalcified in $0.5 \mathrm{~m}$ EDTA, $\mathrm{pH} 8.0$, for $2-4 \mathrm{~d}$ as required. Once decalcified, cochleae were washed once and then dehydrated through an ascending series of ethanol concentrations, equilibrated in propylene oxide, and infiltrated and embedded in epoxy resin (812; TAAB Laboratories). Cochleae were positioned in molds with the oval and round windows facing upward and polymerized at $60^{\circ} \mathrm{C}$ for $24 \mathrm{~h}$. Using a Reichert Ultracut $\mathrm{E}$ ultramicrotome and a diamond knife, $1-\mu \mathrm{m}$-thick sections were obtained in a plane parallel with the base of each cochlear block such that profiles of the $\sim 4,8,20$, and $40 \mathrm{kHz}$ regions could be obtained in a single section. Sections were stained with $1 \%$ toluidine blue, viewed with a Zeiss Axioplan 2 microscope, and images were captured with a Spot RT slider camera at a resolution of $1600 \times 1200$ pixels. For transmission electron microscopy, sections were cut at a thickness of $80-100 \mathrm{~nm}$, mounted on copper mesh grids, stained with uranyl acetate followed by lead citrate, and viewed with an Hitachi 7100 microscope operating at $100 \mathrm{kV}$. Images were captured with a Gatan Ultrascan 1000 CCD camera at $2048 \times 2048$ pixel resolution. Minor adjustments in brightness, contrast and sharpness were made in Adobe Photoshop CS5.

Quantification of holes in the TM matrix. Images of toluidine-bluestained semithin sections photographed with a $40 \times$ objective were imported into Photoshop CS5 and the tectorial membrane selected with the polygonal lasso. Using the thresholding tool, the level was adjusted until only the holes in the TM were white and the rest of the TM was black. Using the histogram tool, the number of white pixels and the total pixel count of the entire TM profile selected by the lasso were recorded. Measurements were taken from 4 different regions of the cochlea estimated to 
have characteristic frequencies (CFs) of $\sim 4,8,20$, and $40 \mathrm{kHz}$. Between four and seven profiles were measured for each region for each genotype. Statistical significance was assessed using one-way ANOVA followed by the Tukey test.

Immunoblotting. To analyze the protein composition of the TM, labyrinths were collected in cold PBS, the bony and lateral walls of the cochlea were removed, and the preparations exposed briefly (for $\sim 2$ $\min$ ) to $0.2 \%$ alcian blue to aid visualization. The TMs were then removed with fine needles, collected in PBS containing $0.1 \%$ Triton X-100, and stored frozen at $-80^{\circ} \mathrm{C}$. TM samples were later solubilized by heating in a reducing SDS-PAGE sample buffer [50 mm Tris- $\mathrm{HCl}, \mathrm{pH} 6.8,2 \%$ SDS $(\mathrm{w} / \mathrm{v}), 10 \%$ glycerol, $0.1 \mathrm{M}$ dithiothreitol, $5 \% \beta$-mercaptoethanol, $0.01 \%$ bromophenol blue], and a volume equivalent to $\sim 2$ TMs was loaded into each lane of a polyacrylamide step gradient gel. The stacking gel was composed of $4 \%$ acrylamide and the upper and lower halves of the separating gel were composed of $8.25 \%$ and $12 \%$ acrylamide, respectively. Prestained color markers (Bio-Rad) and a biotinylated protein ladder for HRP detection (Cell Signaling Technology) were used as molecular mass markers. Separated proteins were electroblotted onto PVDF membranes overnight and after 90 min preblocking with 3-4\% nonfat dry milk in TBS containing $0.15 \%$ Tween 20 , the membranes were incubated overnight in rabbit anti-CEACAM16 (Zheng et al., 2011) or a mixture of rabbit antibodies directed against TECTA, TECTB, and collagen IXa. Antibodies to collagen IXa were obtained from Calbiochem and were used at a dilution of 1:1500. Antibodies to TECTA and TECTB were raised to peptides based on the predicted amino acid sequences of each protein (CGRLEIHRNKNSTTVESK and CYNKNPLDDFLRPDGR for mouse TECTA and YQFVIPDLSPKNKSYC and CPTDETVLVHENGKDH for mouse TECTB), affinity purified on immobilized peptides (CYNKNPLDDFLRPDGR for mouse TECTA and CPTDETVLVHENGKDH for mouse TECTB), and used at working concentrations of $0.2 \mu \mathrm{g} / \mathrm{ml}$ (anti-TECTA) and $0.4 \mu \mathrm{g} / \mathrm{ml}$ (anti-TECTB). Control experiments demonstrated that the three antibodies were, when used in isolation, specific for their respective antigens. HRP-conjugated goat anti-rabbit IgG (True Blot; Rockland) was used to detect the bound primary antibodies and was visualized using enhanced chemiluminiscence (Immobilon; Millipore). Densitometric analysis was performed using ImageJ software. Values for the TECTA, TECTB, and CEACAM16 bands were expressed relative to those of the collagen IXa bands, which were used as an internal standard. Values for TECTA, TECTB, and CEACAM16 from Ceacam $16^{+/ \beta \mathrm{gal}}$ and Ceacam $16^{\beta \mathrm{gal} /} \beta \mathrm{gal}$ mice were then normalized to their respective relative value in WT mice in each independent experiment. The analysis was repeated $3 \times$ with TMs obtained from separate batches of animals.

Immunoprecipitation. HEK-293 EBNA cells at $\sim 75 \%$ confluence in 35-mm-diameter plastic Petri dishes were singly transfected with plasmid constructs encoding myc-TECTA, CEACAM16-V5-His, or EGFPTECTB or were cotransfected with a mixture of myc-TECTA and CEACAM16-V5-His or a mixture of EGFP-TECTB and CEACAM16V5-His. Transfection complexes were prepared in $500 \mu$ l of OptiMEM using 2 or $4 \mu \mathrm{g}$ of DNA (for single and cotransfections, respectively) and $10 \mu \mathrm{l}$ of Lipofectamine 2000 (Invitrogen). Cells were incubated with the DNA/Lipofectamine complexes in serum containing medium $(90 \%$ DMEM, $10 \%$ fetal bovine serum) for $36-48 \mathrm{~h}$, and for a further $2-3 \mathrm{~d}$ in serum-free medium. After removal of the medium, the cells were washed with PBS, scraped from the dishes, collected by centrifugation and frozen at $-20^{\circ} \mathrm{C}$. Frozen pellets were thawed on ice in $500 \mu \mathrm{l}$ of lysis buffer $(1 \%$ Triton X-100, 1\% Sigma protease inhibitor P8340 in PBS), incubated for $1 \mathrm{~h}$ on a rocker at $4^{\circ} \mathrm{C}$ and centrifuged at $10,000 \times$ g for $15 \mathrm{~min}$ at $4^{\circ} \mathrm{C}$. The resultant supernatants $(500 \mu \mathrm{l})$ were incubated overnight with $2 \mu \mathrm{g}$ of mouse monoclonal anti-V5 antibody (Invitrogen) at $4^{\circ} \mathrm{C}$ with gentle mixing on a rocker. Immune complexes were collected with protein A-Sepharose (Sigma-Aldrich) that had been preincubated in $2.5 \%$ BSA in PBS overnight at $4^{\circ} \mathrm{C}$ before use. A $50 \mu \mathrm{l}$ of volume of a 1:1 protein A-Sepharose:PBS slurry was added to each reaction and the samples were incubated for a further $24 \mathrm{~h}$ at $4^{\circ} \mathrm{C}$. The beads were then collected by centrifugation at $3000 \times g$ for 2 min, washed $2 \times$ with PBS and $1 \times$ with TBS, and the bound proteins eluted by heating at $100^{\circ} \mathrm{C}$ for $8 \mathrm{~min}$ in $30 \mu \mathrm{l}$ of $2 \times$ concentrated reducing SDS-PAGE sample buffer. Eluted samples were run on $10 \%$ polyacrylamide SDS gels and transferred to Hybond-P PVDF membranes (GE Healthcare) using wet electroblotting. After preblocking (see Immunoblotting, above), membranes were incubated overnight in mouse monoclonal anti-myc (clone 9E10) or rabbit antiGFP (Invitrogen). HRP-conjugated goat anti-mouse IgG (Cell Signaling Technology) or HRP-conjugated goat anti-rabbit IgG (Trueblot; Rockland) were used to detect the bound primary antibodies.

Auditory brainstem responses. To evaluate neural output, auditory brainstem response (ABR) thresholds were obtained for tone bursts (10 $\mathrm{ms}$ duration including the $1 \mathrm{~ms}$ rise/fall times) and brief transients (100 $\mu \mathrm{s})$ created by gating a $16 \mathrm{kHz}$ tone and using a Card Deluxe 24 bit sound card with a sampling rate of $96 \mathrm{kHz}$. This card was used for all of the physiological measurements. Recording electrodes were placed at the vertex, the mastoid, and in the neck region on the opposite side of the head. Potentials from the vertex and mastoid were measured relative to the indifferent electrode in the neck. These potentials were then differentially amplified $($ gain $=1000)$ and averaged. Samples increased from 1000 to 6000 as the signal level decreased. Threshold was designated as the level where the $\mathrm{ABR}$ response disappeared into the noise.

Otoacoustic emissions. Brief descriptions of the different types of otoacoustic emissions (OAEs) are provided at the appropriate locations in the Results section. Because OAEs are thought to arise in the process of hair cell transduction (Jaramillo et al., 1993; Manley et al., 2001; Mom et al., 2001; Lukashkin and Russell, 2002; Siegel et al., 2005; Siegel, 2006), they were chosen to study changes in physiology early in the signal-coding pathway and before inner hair cell (IHC) transduction. Distortion product emissions (DPOAEs) were recorded from the closed ear canal using a custom probe that incorporates a sensitive Knowles FG-3652-CX microphone. EMAV (Neely and Liu, 1994) and additional computer programs written in Visual Basic 6.0 were used to collect and analyze the emission responses. Because the probe can be placed close to the eardrum, sound calibrations in the ear canal of each individual mouse were performed using SysRes (Neely and Stevenson, 1992). The transfer function of the emission probe's microphone was measured (Siegel, 2007) and used to compensate canal pressures. DPOAEs were measured as iso-input functions obtained by varying the frequency of $\mathrm{F} 2$ while leaving the frequency ratio $(\mathrm{F} 2 / \mathrm{F} 1=1.2)$ constant. We also collected input-output functions for $\mathrm{F} 2=12$ and $\mathrm{F} 2=27 \mathrm{kHz}$. To obtain a measure of F2-F1, in addition to the more commonly recorded $2 \mathrm{~F} 1-\mathrm{F} 2$, we acquired an input-output function for $\mathrm{F} 2=23 \mathrm{kHz}$ and $\mathrm{F} 2 / \mathrm{F} 1=1.4$. A change in parameters was required to produce F2-F1 within the mouse audiogram for stimulus tones that were not especially high in frequency, where even WT responses are inherently variable.

We also recorded spontaneous (SOAE), stimulus frequency (SFOAE), and transiently evoked (TEOAE) OAEs. To measure SOAEs, the noise floor in quiet was measured using SysRes by performing a spectral average of 40 samples of the canal pressure into a 524,288 point buffer. A fast Fourier transform (FFT) was performed on the time waveform of each sample and the magnitudes averaged. A moving rectangular window served to smooth the spectrum such that energy was integrated into nonoverlapping windows with a width of $93 \mathrm{~Hz}$. Spontaneous emissions were identified as peaks in the noise spectrum. Because energy in SOAEs is not concentrated into one spectral line, the total power in each SOAE was calculated by integrating the energy in all spectral lines near the peak where the emission deviated from the background noise. Because this value contains the emission signal plus noise in each line, an estimate of the power in the noise was subtracted from the total. This calculation is similar to that described previously (Talmadge et al., 1993).

SFOAEs were measured for probe tones between 4 and $36 \mathrm{kHz}$ using the suppression technique (Siegel et al., 2005). Probe and suppressor were presented using different speakers at 30 and $65 \mathrm{~dB}$, respectively. Suppressor frequency was $86 \mathrm{~Hz}$ below the probe frequency and is assumed to eliminate the SFOAE produced by the probe. Vector subtraction was used to calculate the change in pressure induced by the suppressor and referred to as the residual. If suppression is complete, the residual provides an accurate estimate of the SFOAE. Input-output functions were collected for the probe frequency producing the strongest SFOAE in each individual animal. Threshold was designated as the level that generated a $10 \mathrm{~dB}$ SPL SFOAE. 
The same stimulus frequency used to obtain the SFOAE input-output function was also selected for the TEOAEs recorded using a $0.5 \mathrm{~ms}$ tone burst with rise/fall times of $0.25 \mathrm{~ms}$. Because our sound sources (modified Radio Shack Realistic \#40-1310B Super Tweeters) produce negligible distortion $\angle 80 \mathrm{~dB}$, the pressure measured in the ear canal is dominated by the stimulus at high levels. Because the TEOAE is presumably saturated and contributes little to the canal pressure at high levels, the scale and subtract (compression) method was used to estimate the emission evoked by the stimulus (Kemp and Chum, 1980a, 1980b; Siegel et al., 2011). When acquiring TEOAEs, a sequence of four stimuli were presented as a group. The probe was presented three times and the reference high-level tone was presented once. Responses to the probe tones were averaged separately from the responses to the reference, allowing the latter to be scaled down and subtracted from the averaged probe response. A total of 2048 samples were collected. This procedure effectively cancels the contribution of the stimulus to the measured pressure in the canal. For our recordings, the reference was always presented at $70 \mathrm{~dB}$ peak-equivalent SPL (peSPL) and the probe was introduced at $50 \mathrm{~dB}$ peSPL and then decreased in level to obtain a TEOAE threshold. A recursive-exponential window (duration $4 \mathrm{~ms}$ ) was positioned near the center of the transient-response waveform, which served to minimize the influence of noise outside the windowed time segment. The TEOAE emission spectrum was extracted by performing an FFT on these windowed time waveforms. The TEOAE level reference was equivalent sound exposure level (Goodman et al., 2009).

All of the physiological measurements were obtained on anesthetized mice of both sexes (ketamine $100 \mathrm{mg} / \mathrm{kg}$; xylazine $10 \mathrm{mg} / \mathrm{kg}$, i.p.) and body temperature was maintained at $\sim 38^{\circ} \mathrm{C}$ using a heating blanket. Supplements of anesthesia at $20 \%$ of the dose for induction were administered as needed. At the end of an experiment, the animals were killed with Euthasol $(200 \mathrm{mg} / \mathrm{kg}$, i.p.). All procedures were approved by The University of Sussex and by Northwestern University, as well as by the Home Office in the United Kingdom and the National Institutes of Health in the United States.

Whole-cell patch-clamp recording. Whole-cell nonlinear capacitance (NLC) recordings were performed using the Axopatch 200A amplifier (Molecular Devices). The intracellular solution contained the following (in mM): $140 \mathrm{CsCl}, 2 \mathrm{MgCl}_{2}, 10$ EGTA, and 10 HEPES, pH 7.3. The extracellular solution contained the following (in $\mathrm{mM}$ ): $120 \mathrm{NaCl}, 20$ TEA-Cl, $2 \mathrm{CoCl}_{2}, 2 \mathrm{MgCl}_{2}, 10$ HEPES, pH 7.3. Osmolarity was adjusted to $310 \mathrm{mOsml}^{-1}$ with glucose and intracellular pressure was kept at 0 $\mathrm{mmHg}$ during recording. Data were collected with jClamp (SciSoft Company) using an FFT-based admittance analysis to determine cell membrane capacitance ( $C_{\mathrm{m}}$; Santos-Sacchi et al., 1998). NLC data were analyzed using the following equation:

$$
C_{m}=\frac{\alpha Q_{\max }}{\exp \left[-\alpha\left(V_{m}-V_{p k c m}\right)\right]\left\{1+\exp \left[\alpha\left(V_{m}-V_{p k c m}\right)\right]\right\}^{2}}+C_{l i n}
$$

where $\alpha$ is the slope factor, $Q_{\max }$ is the maximum charge transfer, $V_{\mathrm{m}}$ is the membrane potential, $V_{\mathrm{pkcm}}$ is the voltage at which the maximum charge movement per voltage is attained, and $C_{\operatorname{lin}}$ is the linear capacitance (Homma et al., 2013).

\section{Results}

\section{TECTB levels are reduced in the TMs of Ceacam $16^{\beta}$ gal/ $\beta$ gal} mice

Immunoblot analysis of TM samples obtained from WT, Ceacam $16^{+/ \beta \text { gal }}$, and Ceacam16 $6^{\beta \text { gal } / \beta \text { gal }}$ mice with antibodies to CEACAM16 (Fig. $1 A$ ) reveals that there is, as expected, a complete absence of CEACAM16 protein in the TM of the Ceacam $16^{\beta \mathrm{gal} / \beta \mathrm{gal}}$ mouse (Fig. $1 A$ ). Homozygotes are therefore functionally null mutants. Furthermore, results shown in Figure $1 B$, which were obtained using antibodies to TECTA, TECTB, and collagen IXa, indicate that these three proteins are present in the TM of the Ceacam $16^{\beta \mathrm{gal} / \beta \mathrm{gal}}$ mouse. The antibodies to CEACAM16 detect a closely spaced ladder of eight distinct immunoreactive protein bands in both the WT and the heterozy-
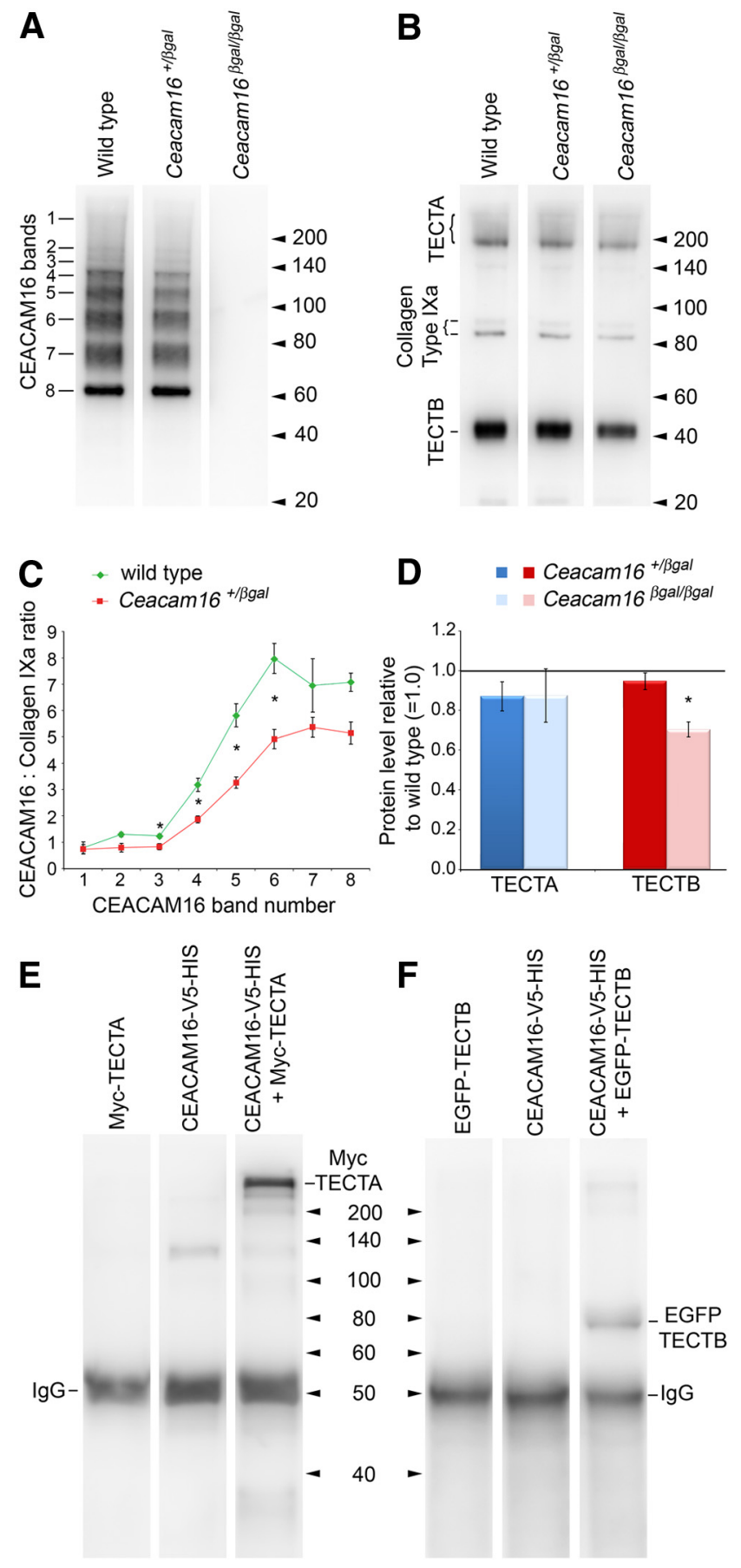

Figure 1. Immunoblotting and immunoprecipitation. $A, B$, Western blots of TMs from WT Ceacam $16^{+/ \beta \text { gal }}$, and Ceacam $16^{\beta \text { gal } / \beta \text { gal }}$ mice stained with antibodies to CEACAM16 $(A)$ and a mixture of antibodies to TECTA, TECTB, and collagen IXa $(\boldsymbol{B}) . \boldsymbol{C}$, $\boldsymbol{D}$, Densitometry of CEACAM16

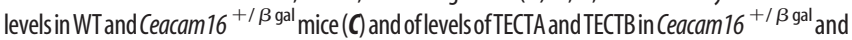
Ceacam $16^{\beta \text { gal/ } / \beta \text { gal }}$ mice relative to those in WT controls (D). Multiple comparisons were made by one-way ANOVA, followed by $t$ tests to determine pairwise differences among the groups used in each experiment. Asterisks in $\boldsymbol{C}$ and $\boldsymbol{D}$ indicate values that are significantly different at $p<0.01$. $\boldsymbol{E}, \boldsymbol{F}$, Immunoblots of proteins immunoprecipitated with anti-V5 monoclonal antibody and protein A-Sepharose from lysates prepared from HEK293-EBNA cells that were singly or cotransfected with plasmid DNAs as indicated above each lane. Blots in $\boldsymbol{E}$ were stained with mouse monoclonal anti-myc antibody (clone 9E10); blots in $\boldsymbol{F}$ with polyclonal rabbit anti-GFP antibody. Myc-TECTA ( $\boldsymbol{E}$, right lane) and EFGP-TECTB ( $\boldsymbol{F}$, right lane) are coimmunoprecipitated when coexpressed with CEACAM16-V5-His. IgG heavy chain is indicated ( $\lg G)$. 
gous samples that range in mass from 60 to $>200 \mathrm{kDa}$ (Fig. 1A). Some of the bands with apparent masses $>100 \mathrm{kDa}$ may represent multimeric forms of the protein that are covalently coupled by bonds other than a disulfide linkage, because the samples were denatured in the presence of both DTT and $\beta$-mercaptoethanol before gel electrophoresis. Other bands may be due to variations in posttranslational modifications such as glycosylation or phosphorylation. Densitometric analysis (Fig. $1 C$ ) indicates that the levels of some of the CEACAM16 bands (labeled 3 through 6 in Fig. $1 A)$ are significantly reduced $(p<0.01)$ relative to collagen IXa levels in the Ceacam $16^{+/ \beta \text { gal }}$ mice compared with those in WT controls. This observation may indicate a degree of protein insufficiency in the heterozygotes. Densitometric analysis of the levels of TECTA and TECTB in Ceacam16 ${ }^{+/ \beta \text { gal }}$ and Ceacam $16^{\beta \text { gal/ } \beta \text { gal }}$ mice relative to those in WT controls (Fig. 1D) demonstrates that TECTA levels are unchanged ( $p=0.54$, oneway ANOVA), but that TECTB levels in the Ceacam $16^{\beta \mathrm{gal} / \beta \mathrm{gal}}$ mouse are significantly reduced (by $\sim 30 \%$ ) relative to those in either the Ceacam16 $6^{+/ \beta \mathrm{gal}}$ or the WT control $(p<0.01, t$ test). Differences were not significant $(p=0.14)$ between WT and heterozygous mice.

In light of these results, coimmunoprecipitation experiments were used to determine whether TECTB and CEACAM16 interact. As shown previously (Zheng et al., 2011), myc-tagged TECTA can be coimmunoprecipitated from cell lysates by antibodies to V5 when coexpressed with V5-His tagged CEACAM16 (Fig. 1E). Likewise, EGFP-tagged TECTB can be coimmunoprecipitated with anti-V5 antibody when coexpressed with V5-His tagged CEACAM16 (Fig. $1 F$ ). These data suggest that CEACAM16 is able to interact with both TECTA and TECTB.

\section{Ceacam 16 is expressed by nonsensory cells in the organ of Corti}

In Ceacam $16^{+/ \beta \text { gal }}$ and Ceacam16 $6^{\beta \text { gal } / \beta \text { gal }}$ mice, $\mathrm{X}$-Gal staining for the $\beta$-galactosidase reporter reveals Ceacam 16 gene activity; that is, it shows the cells that would be expected to produce CEACAM16 in WT mice. Figure $2 A$ shows the expression pattern for the reporter gene in a representative $20 \mu \mathrm{m}$ section obtained near the middle of the cochlea at P21 from a Ceacam $16^{\beta \mathrm{gal} / \beta \mathrm{gal}}$ mouse. Strong X-Gal staining is seen in epithelial cells of the spiral limbus and inner sulcus, border cells, inner and outer pillar cells, and Deiters' cells. Staining is not detected within the IHCs or OHCs (Fig. 2A). Weak staining observed toward the apices of the OHCs may be due to expression in the phalangeal processes of Deiters' cells. Confocal microscopy of sections double labeled for $\beta$-galactosidase and F-actin was therefore used to generate highresolution images with a shallow $(0.63 \mu \mathrm{m})$ optical depth (Fig. $2 B)$. These images further indicate that expression is strong in Deiters' cells, but absent from the OHCs that they ensheath. CEACAM16, a protein with a signal sequence for translocation into the endoplasmic reticulum that lacks a transmembrane domain (Zheng et al., 2011), is therefore expressed by cochlear supporting cells, secreted, and incorporated into the matrix of the TM.

\section{Loss of striated-sheet matrix and Hensen's stripe in Ceacam 16 ${ }^{\beta \mathrm{gal} / \beta \mathrm{gal}}$ mice}

Because it is known that tectorins form the striated-sheet matrix within which the collagen fibers are imbedded (Hasko and Richardson, 1988) and because CEACAM16 binds TECTA (Zheng et al., 2011) and TECTB (Fig. $1 F$ ), the main body of the TM was examined using light microscopy and toluidine blue staining. The morphology of the mature tectorial membrane in WT,
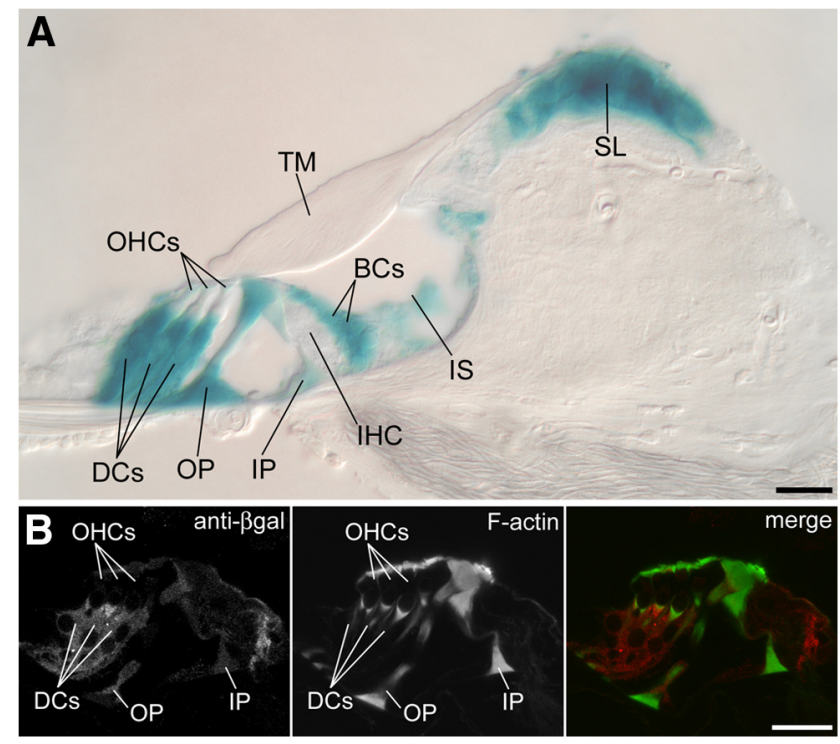

Figure 2. Ceacam16 is expressed by nonsensory cells in the organ of Corti. $\boldsymbol{A}, \mathrm{X}$-Gal staining for $\beta$-galactosidase reporter expression in the basal coil ( $\sim 20 \mathrm{kHz}$ region) of a Ceacam $16^{\beta \text { gal } / \beta \text { gal }}$ mouse at P21. X-Gal staining is observed in Deiters' cells (DCs), inner pillar cells (IP), outer pillar (OP) cells, border cells (BCs), and epithelial cells of the inner sulcus (IS) and spiral limbus (SL). OHCs, IHCs, and the TM are also indicated for reference. $\boldsymbol{B}$, Immunofluorescence. A single confocal slice ( $0.63 \mu \mathrm{m}$ optical thickness) of an organ of Corti cryosection from a P21 Ceacam $16^{\beta \text { gal } / \beta \text { gal }}$ mouse stained with anti- $\beta$ gal (red) and phalloidin to label F-actin (green). $\beta$ gal is observed in Deiters' cells (DCs), outer pillar cells (OP) and inner pillar cells (IP), but not in hair cells. Scale bars, $20 \mu \mathrm{m}$.

Ceacam16 ${ }^{+/ \beta \mathrm{gal}}$ (heterozygous), and Ceacam16 ${ }^{\beta \mathrm{gal} / \beta \mathrm{gal}}$ (homozygous) mice is provided in Figure 3 using cross-sectional profiles at the light microscope level. Although the TMs of WT (Fig. 3A-C) and Ceacam16 $6^{+/ \beta \text { gal }}$ (Fig. 3D-F) mice are comparable, the TM of Ceacam $16^{\beta \mathrm{gal} / \beta \mathrm{gal}}$ mice possesses large holes in the matrix that are particularly conspicuous in apical, low-frequency regions (Fig. $3 G$ ), but are also present to a lesser degree in more basal regions (Fig. $3 H, I$ ). Although holes are seen in WT and heterozygous TMs, they are small and few in number. Morphometric analysis indicates the percentage of the TM cross-sectional area occupied by these holes is significantly increased $(p<0.001)$ relative to that in WT or heterozygous mice in all four regions of the cochlea that were analyzed (Fig. $3 J-L$ ). The area occupied by holes in homozygous mutants decreases as the CF of the region increases (Fig. $3 J$ ). Areas occupied by holes in WT and heterozygous mice were not significantly different $(p>0.05)$ in any cochlear location analyzed.

In sections from basal regions of the cochleae in WT and Ceacam $16^{+/ \beta \text { gal }}$ mice, a ridge known as Hensen's stripe is observed on the underside of the TM in close proximity to the IHC hair bundle (Fig. $3 C, F$ ), but is absent from similar regions of the $\mathrm{TM}$ in Ceacam $16^{\beta \mathrm{gal} /} \beta$ gal mice (Fig. $3 I$ ). However, independent of genotype, a distinct stripe is not observed in apical regions (Fig. $3 A, D, G)$. In alcian-blue-stained whole-mount preparations of TMs viewed by phase-contrast microscopy, Hensen's stripe is also visible as a prominent ridge in the basal, high-frequency region in WT and Ceacam $16^{+/ \beta \text { gal }}$ mice (Fig. $3 M, N$ ). Analysis of a small sample of WT and heterozygous TMs using this method reveals that the transition (presence-to-absence of Hensen's stripe as assessed by phase-contrast microscopy) occurs at $\sim 3.6$ $\mathrm{mm}$ (at $\sim 60 \%$ of the length) from the base of the cochlea. Based on the frequency-place map of Müller et al. (2005), this position corresponds to a best frequency of $15.4 \pm 4.35 \mathrm{kHz}(n=7)$. 


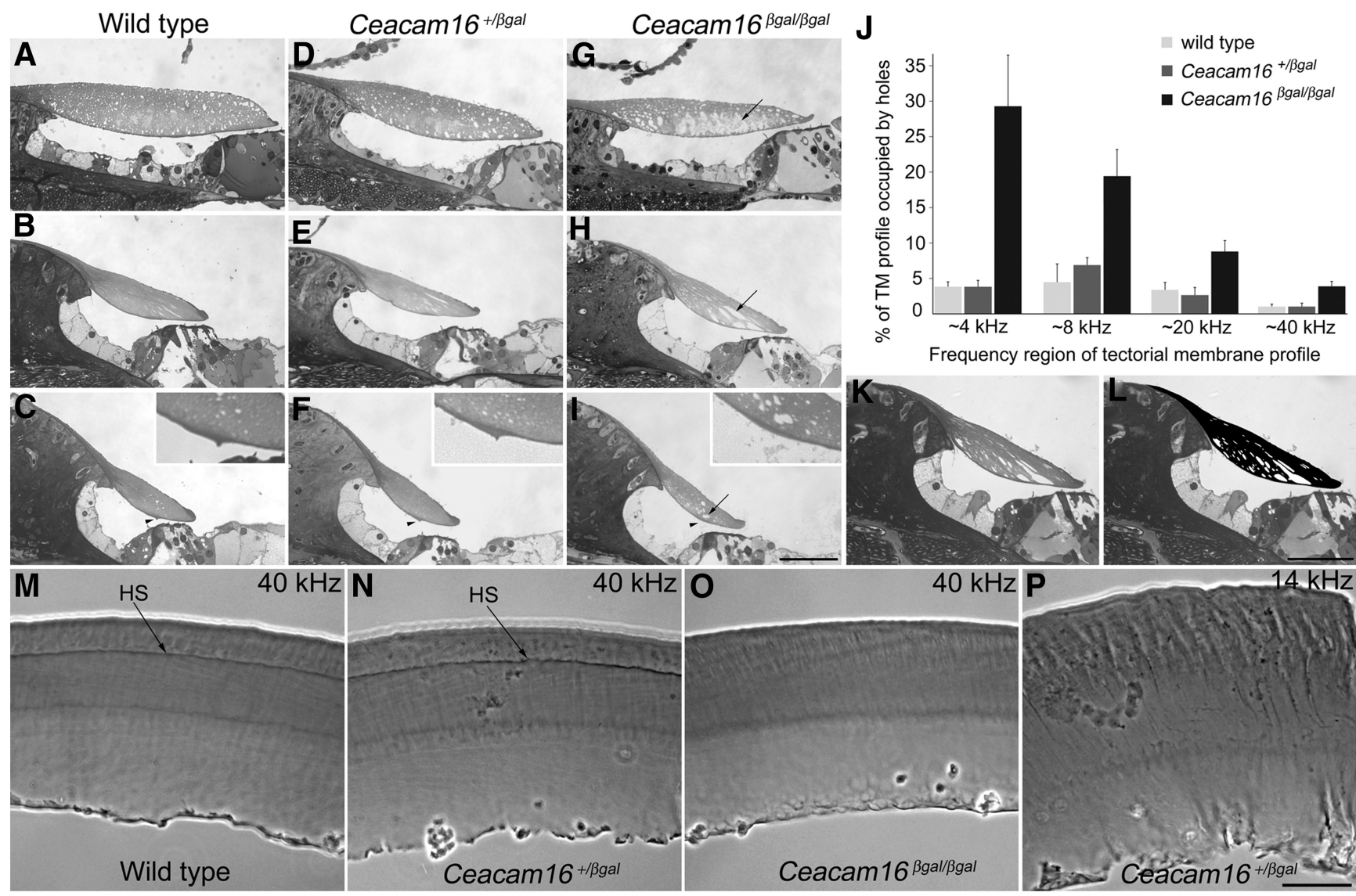

Figure 3. Loss of striated-sheet matrix and Hensen's stripe in the absence of CEACAM16. $\boldsymbol{A}-\boldsymbol{I}$, Toluidine-blue-stained semithin sections from WT $(\boldsymbol{A}-\boldsymbol{C}),\left(\right.$ eacam $16^{+/ \beta}$ gal $(\boldsymbol{D}-\boldsymbol{F})$, and Ceacam $16^{\beta \text { gal } / \beta \text { gal }}(\boldsymbol{G}-\boldsymbol{I})$ mice from the $\sim 8 \mathrm{kHz}(\boldsymbol{A}, \boldsymbol{D}, \boldsymbol{G}), 20 \mathrm{kHz}(\boldsymbol{B}, \boldsymbol{E}, \boldsymbol{H})$, and $\sim 40 \mathrm{kHz}(\boldsymbol{C}, \boldsymbol{F}, \boldsymbol{I})$ regions of the cochlea are provided at P43. Hensen's stripe, although visible in the $\sim 40 \mathrm{kHz}$ region of WT (arrowhead in $C$ ) and Ceacam $16^{+/ \beta \text { gal }}$ (arrowhead in $\boldsymbol{F}$ ) TM is not present in the equivalent region of the Ceacam $16^{\beta}$ gall $\beta$ gal $T M$ (arrowhead in $I$ ). Insets show the Hensen's stripe

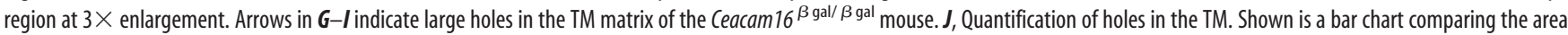
occupied by holes in the TMs of WT, Ceacam $16^{+/ \beta}$ gal , and Ceacam $16^{\beta}$ gal/ $\beta$ gal mice from four different regions of the cochlea between P30 and P43. Data from between four and seven TM profiles were used for each region and genotype. TM profiles from (eacam $16^{\beta}$ gal $/ \beta$ gal mice have significantly more space occupied by holes $(p<0.001)$ than either WT or $\left(e a c a m 16^{+/ \beta \text { gal }}\right.$ mice in all regions examined. $\boldsymbol{K}$ - $\boldsymbol{L}$, Toluidine-blue-stained section of an $\sim 20 \mathrm{kHz}$ cochlear profile from a P43 Ceacam $16^{\beta \text { gal/ } \beta \text { gal }}$ mouse before $(\boldsymbol{K})$ and after $(\boldsymbol{L})$ using Photoshop to threshold adjust the TM to distinguish matrix from holes. $\boldsymbol{M}-\boldsymbol{P}$, Phase-contrast images of alcian-blue-stained TMs from WT $(\boldsymbol{M})$, Ceacam $16^{+/ \beta \text { gal }}(\boldsymbol{N}, \boldsymbol{P})$, and Ceacam $16^{\beta \text { gal/ } \beta \text { gal }}(\mathbf{O})$ mice. Images in $\boldsymbol{M}-\mathbf{0}$ are from the $\sim 40 \mathrm{kHz}$ region; image in $\boldsymbol{P}$ is from the $\sim 14 \mathrm{kHz}$ region. $\mathrm{HS}$, Hensen's stripe. Scale bars, $50 \mu \mathrm{m}$.

Phase-contrast microscopy of whole-mount preparations confirms that Hensen's stripe is not present in the high-frequency region of the TM in Ceacam16 ${ }^{\beta \mathrm{gal} /} \beta \mathrm{ggal}$ mice (Fig. 3O) or in the apical, lower-frequency regions of WT (data not shown) and Ceacam $16^{+/ \beta \text { gal }}$ (Fig. 3P) mice.

Ultrastructural examination of the TM reveals a number of defects (Fig. 4). In WT and Ceacam $16^{+/ \beta \text { gal }}$ mice, covernet fibrils run longitudinally along the upper surface of the TM and are connected to the striated-sheet matrix (Fig. $4 A$ ). In Ceacam $16^{\beta \text { gal } / \beta \text { gal }}$ mice, although covernet fibrils are present, they are imbedded in a dense amorphous matrix (Fig. $4 B$ ) and the striated-sheet matrix typical of the central core of the normal TM (Fig. 4C, arrow) is replaced with a loose arrangement of tangled filaments (Fig. $4 D$, arrow). Collagen fibril organization and distribution appear normal in the Ceacam $16^{\beta \text { gal/ } \beta \text { gal }}$ mutant mouse (Fig. $4 D$, arrowhead). Consistent with the observations described in the preceding paragraph, Hensen's stripe presents as a distinct, $\mathrm{V}$-shaped ridge on the lower surface of the TM in the basal region of the cochlea in WT (data not shown) and Ceacam $16^{+/ \beta \text { gal mice }}$ (Fig. $4 E$ ). In Ceacam $16^{\beta \mathrm{gal} / \beta \text { gal }}$ mice, a thickening of the dense amorphous lower surface is all that can be observed in this region (Fig. $4 F$ ).
Ceacam 16 expression correlates with the appearance of striated-sheet matrix

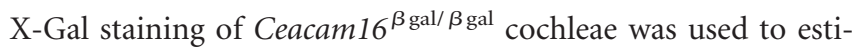
mate the onset of Ceacam 16 expression in the organ of Corti (Fig. $5 A-F)$. Labeling of the border cells, together with staining of Deiters' and epithelial cells of the spiral limbus and inner sulcus, is seen at P12, but only in the basal region of the cochlea (Fig. 5A). Staining is first seen in the apical coil at P14, where labeling is predominantly in the spiral limbus (Fig. 5E). However, by P16, clear labeling of border cells and Deiters' cells is also seen in apical coil sections (Fig. 5F). Ultrastructural analysis of the central core of the TM in the apex of WT animals during these developmental stages reveals that, at P12 and earlier, the matrix of the apical coil TM consists of a disorganized meshwork of filaments in addition to rows of parallel collagen fibrils (Fig. $5 G$ ). This appearance is similar to that seen at mature stages in mutant mice (Fig. $4 D$ ). At P14, this noncollagenous matrix becomes condensed and more organized (Fig. $5 \mathrm{H}$ ) and, by P16, the striated-sheet matrix characteristic of the mature cochlea is clearly apparent (Fig. 5I). These results suggest that there is a base to apex developmental progression in the expression of Ceacam16 that correlates with matura- 


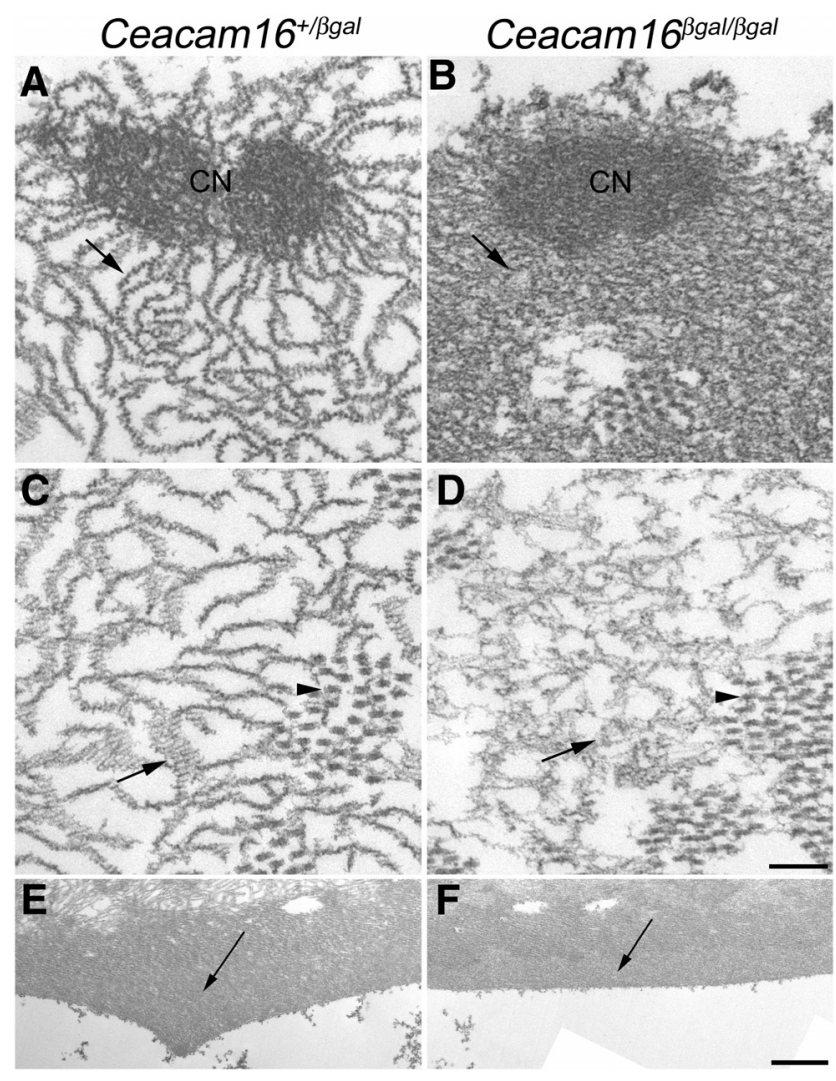

Figure 4. Ultrastructural examination of the TM. $A-D$, Electron micrographs of the covernet $(C N)(\boldsymbol{A}, \boldsymbol{B})$ and central region $(\boldsymbol{C}, \boldsymbol{D})$ of apical-coil TMs from P30 Ceacam16 ${ }^{+/ \beta}$ gal $(\boldsymbol{A}, \boldsymbol{C})$ and Ceacam $16^{\beta \text { gall }} \boldsymbol{\beta \text { gal }}(\boldsymbol{B}, \boldsymbol{D})$ animals. Striated-sheet matrix (arrow in $\boldsymbol{A}$ ) emanates from the densely packed fibrils of the covernet in Ceacam $16^{+/ \beta}$ gal mice, whereas in Ceacam $16^{\beta \text { gal } / \beta \text { gal }}$ mice, covernet fibrils are embedded in a dense amorphous matrix ( $\operatorname{arrow}$ in $\boldsymbol{B}$ ). The central core of the TM from (eacam $16^{+/ \beta \text { gal }}$ mice contains striated-sheet material (arrow in $C$ ) intermingled with collagen fibrils (arrowhead in C), whereas in (eacam $16^{\beta \text { gal/ } \beta \text { gal }}$ mice, the striated-sheet matrix is replaced by a tangled meshwork of filaments (arrow in $\boldsymbol{D}$ ) interspersed between collagen fibrils of typical appearance (arrowhead in $\boldsymbol{D}$ ). $\boldsymbol{E}-\boldsymbol{F}$, Electron micrographs of Hensen's stripe in basal-coil TMs from P43 Ceacam16 ${ }^{+/ \beta \text { gal }}(\boldsymbol{E})$ and Ceacam $16^{\beta \text { gal } / \beta \text { gal }}(\boldsymbol{F})$ animals. Dense material on the underside of the TM (arrow in $\boldsymbol{E}$ ) forms a distinctive, $V$-shaped Hensen's stripe in Ceacam $16^{+/ \beta \text { gal }}$ mice (E). In Ceacam $16^{\beta \text { gal } / \beta \text { gal }}$ mice, however, this material (arrow in $\boldsymbol{F}$ ) forms a flattened band on the underside of the TM $(\boldsymbol{F})$. Scale bars: $\boldsymbol{D}, 200 \mathrm{~nm}$ and applies to $\boldsymbol{A}-\boldsymbol{D}$; $\boldsymbol{F}, 1 \mu \mathrm{m}$ and applies to $\boldsymbol{E}-\boldsymbol{F}$.

tion of the TM and that CEACAM16 is required for the formation of the striated-sheet matrix.

\section{ABRs in mutant mice}

Before measuring any physiological responses, we constructed cytocochleograms for Ceacam $16^{\beta \text { gal/ } \beta \text { gal }}$ mice at $\mathrm{P} 43$ to rule out the possibility that hair cell death might influence the recordings. Although not shown here, a loss of hair cells was not observed in mice lacking CEACAM16 at this age.

Data in Table 1 show that ABR thresholds in homozygous mutants at $4 \mathrm{kHz}$ are modestly elevated and statistically different from WT (Student's $t$ test). Thresholds at higher frequencies and for a $100 \mu$ s transient showed no significant difference between mice lacking CEACAM16 and their controls. The threshold shift at the lowest (for the mouse) frequency is consistent with that described previously (Kammerer et al., 2012). We did not, however, observe any magnitude reductions at moderate and high levels of stimulation, which contrasts with the previous study on mice lacking CEACAM16.

\section{DPOAEs in mice lacking CEACAM16 are WT like}

In addition to the $\mathrm{ABR}$ recordings that document summed neural responses at the output of the cochlea, we collected OAEs to study changes occurring earlier in the signal-coding pathway. Otoacoustic emissions are sounds recorded in the ear canal that are not present in the incoming sound stimuli (Avan et al., 2013). Although their existence was predicted by Gold (1948), it was Kemp (1978) who provided experimental verification of their existence. Although OAEs are not involved directly in signal coding, their observation does require hair cells with functional transducer currents and the driving forces required to amplify these currents. Therefore, emissions are extremely useful in evaluating cochlear function, especially in very small animals. One class, DPOAEs, is produced using a two-tone input, F1 and F2, with the most prominent intermodulation frequency being 2F1-F2.

Average distortion product otoacoustic emission or DPgrams $( \pm 1 \mathrm{SD})$ are shown in Figure $6 A$ for $\mathrm{L} 1=50 \mathrm{~dB}, \mathrm{~L} 2=35$ $\mathrm{dB}$ and in Figure $6 B$ for $\mathrm{L} 1=\mathrm{L} 2=70 \mathrm{~dB}$. At the lower sound level, small changes in magnitude, albeit of apparent statistical significance, are obtained for F2 $=13.5 \mathrm{kHz}(\mathrm{DP}=9 \mathrm{kHz})$ and $15.5 \mathrm{kHz}(\mathrm{DP}=10.3 \mathrm{kHz})$. A statistical difference was also obtained at F2 $=40.9 \mathrm{kHz}$. At $70 \mathrm{~dB}$, the only difference associated with the absence of CEACAM16 occurs at F2 $=47 \mathrm{kHz}$, the highest frequency that we tested. Input-output functions were also collected for $\mathrm{F} 2$ at $12 \mathrm{kHz}(\mathrm{DP}=8 \mathrm{kHz})$ and for $\mathrm{F} 2$ at $27 \mathrm{kHz}$ $(\mathrm{DP}=18 \mathrm{kHz})$ (Fig. $6 C, D$, respectively). In neither case was a statistically significant difference seen, even at moderate input levels. Because the $8 \mathrm{kHz}$ DP measured by the input-output function (Fig. 6C) showed no difference between mice lacking CEACAM16 versus WT, one might question the observation that the $9 \mathrm{kHz}$ DP had an apparently significant magnitude reduction in the DP-gram (Fig. 6B).

Based on the previous suggestion that lack of CEACAM16 protein might weaken the attachment between $\mathrm{OHC}$ stereocilia and the TM (Zheng et al., 2011), we speculated that removal of this protein might result in an increased quadratic distortion product, F2-F1, relative to the cubic component at 2F1-F2. This expectation relates to the observation that the set point of the $\mathrm{OHC}$ transducer is located at a position where the slope of the function is steep such that cubic DPs predominate (Russell and Kössl, 1992). Based on previous speculations about F2-F1 and set point changes (Frank and Kössl, 1996), we recorded input-output functions for F2 $=23.5 \mathrm{kHz}, \mathrm{F} 1=16.8 \mathrm{kHz}(\mathrm{F} 2-\mathrm{F} 1=6.7$ $\mathrm{kHz}$ ) and for $\mathrm{F} 2 / \mathrm{F} 1=1.4$. Our unpublished data indicate that such an increase in frequency ratio serves to maximize the F2-F1 component without reducing 2F1-F2 dramatically. For parameters used in the DP-grams of Figure 6, $A$ and $B$, F2-F1 falls within the audiogram, but only for the very highest $\mathrm{F} 2$ frequencies. The variability of high-frequency responses even in WT mice makes it difficult to make quantitative comparisons between mice of different genotype. We, therefore, used a larger frequency ratio and a lower F2 frequency. Data indicate that 2F1-F2 (Fig. 6E) and F2-F1 (Fig. $6 F$ ) are similar in WT, Ceacam $16^{+/ \beta \text { gal }}$ and Ceacam $16^{\beta \text { gal } / \beta \text { gal }}$ mice; that is, there is no change in the relative production of cubic and quadratic components associated with an absence of CEACAM16. It should also be noted again that we do not observe decreased DPOAE outputs for moderate- and high-level primaries. Notably, no dramatic changes were seen in cochlear function in young Ceacam $16^{\beta \mathrm{gal} / \beta \mathrm{gal}}$ mice, except for the threshold elevation in the ABRs at frequencies approaching the lower limit of the murine audiogram. However, older mice lacking CEACAM16 show a progressive loss of sensitivity (Kam- 

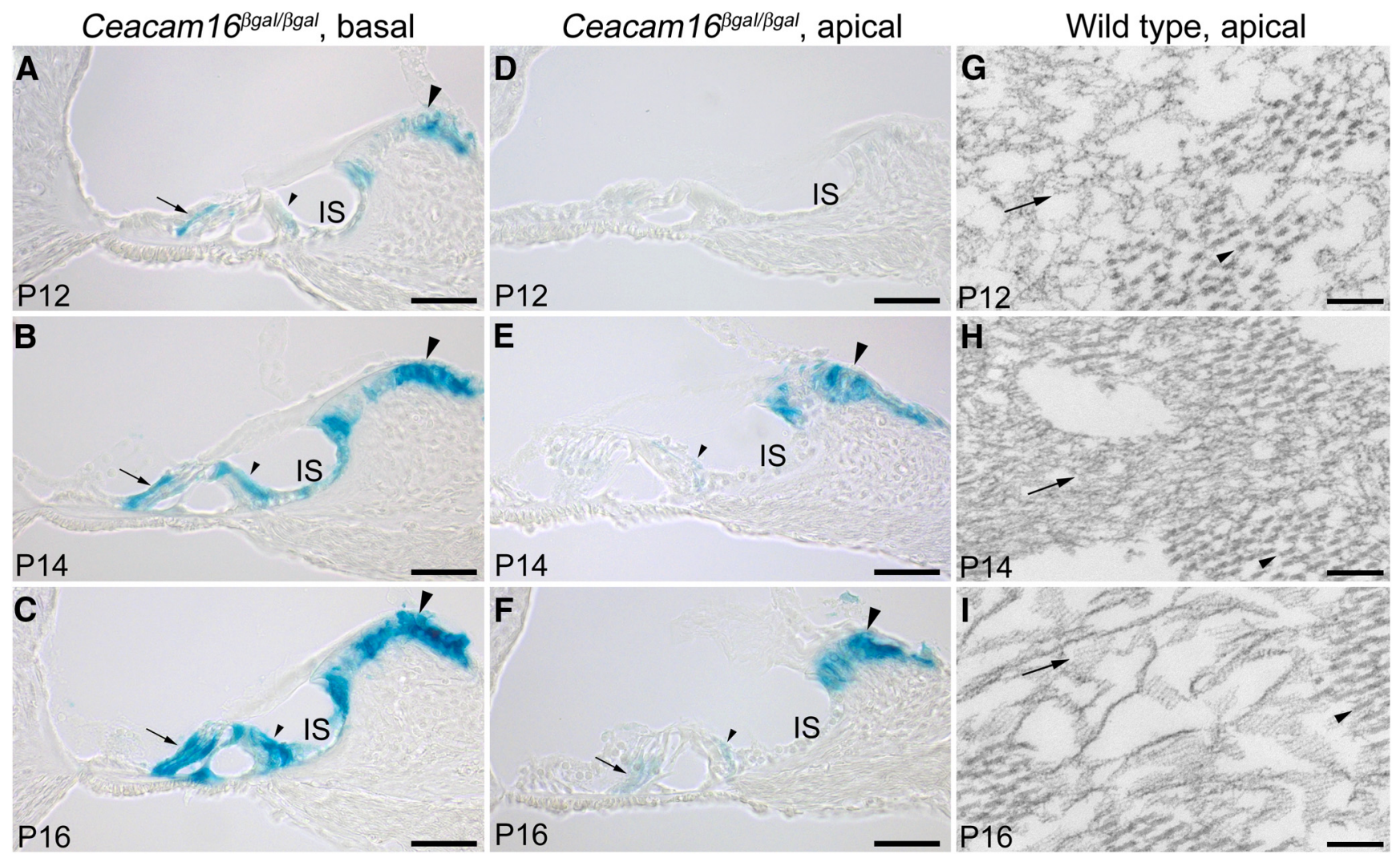

Figure 5. Developmental expression of Ceacam 16. $\boldsymbol{A}-\boldsymbol{F}$, Cryosections from the basal $(\boldsymbol{A}-\boldsymbol{C})$ and apical $(\boldsymbol{D}-\boldsymbol{F})$ regions of X-Gal-stained cochleae from Ceacam $16^{\beta}$ gal/ $\beta$ gal mice at P12 $(\boldsymbol{A}, \boldsymbol{D}), \mathrm{P} 14$ $(\boldsymbol{B}, \boldsymbol{E})$, and P16 $(\boldsymbol{C}, \boldsymbol{F})$. Large and small arrowheads point to X-Gal staining in the spiral limbus and border cells, respectively. Arrows indicate X-Gal staining in Deiters' cells. Scales bars in $\boldsymbol{A}-\boldsymbol{F}, 50 \mu \mathrm{m}$. $\mathbf{G}-\boldsymbol{I}$, Transmission electron micrographs of the central region of the TM from WT animals in the $\sim 8 \mathrm{kHz}$ region of the apical coil at P12 $(\boldsymbol{G}), \mathrm{P} 14(\boldsymbol{H})$, and P16 (I). Arrows and arrowheads point to developing striated-sheet matrix and collagen fibrils, respectively. Scale bars in $\mathbf{G}-\mathbf{I}, 200 \mathrm{~nm}$.

Table 1. ABR thresholds in WT and Ceacam $16^{\beta \text { gal } / \beta}$ gal mice

\begin{tabular}{|c|c|c|c|c|c|c|}
\hline & $4 \mathrm{kHz}$ & $8 \mathrm{kHz}$ & $12 \mathrm{kHz}$ & $27 \mathrm{kHz}$ & $32 \mathrm{kHz}$ & Click \\
\hline \multicolumn{7}{|l|}{ WT $(n=14)$} \\
\hline Average & 45.8 & 34.0 & 31.9 & 20.3 & 28.9 & 31.7 \\
\hline SD & 4.5 & 1.7 & 4.0 & 6.8 & 15.6 & 4.4 \\
\hline \multicolumn{7}{|l|}{$\begin{array}{c}\text { Ceacam } 16^{\beta \mathrm{gal} /} / \mathrm{gal} \\
(n=14)\end{array}$} \\
\hline Average & 50.1 & 38.8 & 33.0 & 25.3 & 29.3 & 33.3 \\
\hline SD & 5.5 & 9.0 & 4.1 & 6.8 & 13.0 & 3.6 \\
\hline Student's $t$ test & $p=0.049$ & $p=0.338$ & $p=0.518$ & $p=0.098$ & $p=0.941$ & $p=0.346$ \\
\hline
\end{tabular}

Data are shown as dB SPL. Mice lacking (EACAM16 have higher thresholds than controls, but these are statistically different (Student'st test) only at $4 \mathrm{kHz}$, a very low frequency for the mouse. Although not shown here, heterozygous mice are WT like.

merer et al., 2012), as do DFNA4B patients with the T140P missense mutation that is thought to destabilize CEACAM16.

\section{Enhanced SOAEs, SFOAEs, and TEOAEs in Ceacam16 mutant mice}

Although DPOAEs dominate measurements described in the literature, OAEs can also be generated using single-tone inputs: SFOAEs and TEOAEs. This latter classification is a somewhat arbitrary parsing of the same phenomenon obtained with either continuous tones or acoustic transients, respectively. In other words, SFOAEs coincide with stimulus frequency, whereas TEOAEs are transients generated in response to very short duration broadband inputs. Finally, SOAEs appear as peaks in the Fourier spectrum of the microphone signal recorded from the ear canal in the absence of sound stimulation. Because the phenotype of Ceacam $16^{\beta \mathrm{gal} / \beta \mathrm{gal}}$ mice was mild or unchanged for DPOAEs and ABRs, and because some models (Shera and Guinan, 1999) suggest a difference in mechanism for this latter group of OAEs, we recorded SOAEs, SFOAEs, and TEOAEs. In our experience, the incidence of SOAEs in WT mice is $<3 \%$. In fact, we have recorded only 1 in $51 \mathrm{WT} /$ heterozygous Ceacam $16^{\beta \text { gal }}$ mice and only 2 before working with this mutant and using a large number $(N=78)$ of WT animals. In stark contrast, $70 \%$ of Ceacam $16^{\beta \mathrm{gal} /} \beta \mathrm{gal}$ mice (67 of 95 homozygotes) have SOAEs and some of these are large and numerous. Examples appear in Figure $7 A$. The largest SOAE recorded from a Ceacam $16^{\beta \text { gal/ } \beta \text { gal }}$ mouse is plotted at the bottom in red. The sole SOAE recorded in a WT mouse is in black. Distribution of 150 SOAE frequencies recorded in 67 homozygous Ceacam $16^{\beta \mathrm{gal} / \beta \mathrm{gal}}$ mice is provided in Figure $7 B$. They range between 14.9 and $32.1 \mathrm{kHz}$. This bar graph represents the number of SOAEs present in each $\mathrm{kHz}$ bin, such that the largest number of SOAEs falls in the bin ranging from 23.000 to 23.999 $\mathrm{Hz}$. When multiple SOAEs are present, their average separation is $2470 \mathrm{~Hz}$; that is, $\sim 10 \%$ of the most common SOAE frequency. The distribution of SOAEs based on their overall SPL is provided in Figure $7 C$. The average SPL for mice lacking CEACAM16 was $17.0 \pm 4.7 \mathrm{~dB}$. The sole WT control had an SOAE of $7.6 \mathrm{~dB}$ (black bar).

Because SOAEs are frequently observed in regions where SFOAEs are large (Shera and Guinan, 2003; Shera, 2003; Banakis et al., 2008), we also recorded SFOAEs across frequency for a 30 $\mathrm{dB}$ probe stimulus. The magnitude of the SFOAE was extracted using the suppression method and, in our case, the suppressor was slightly below the probe frequency and presented at $65 \mathrm{~dB}$. Data in Figure $8 A$ show a representative example where the 


\section{A}

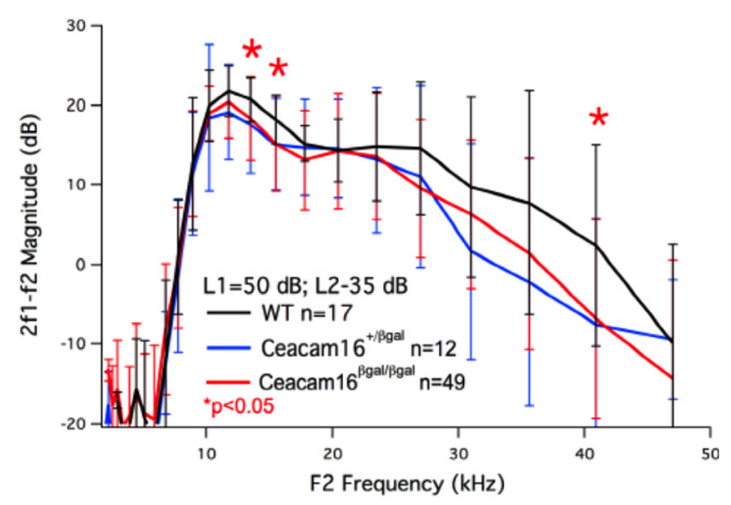

\section{B}

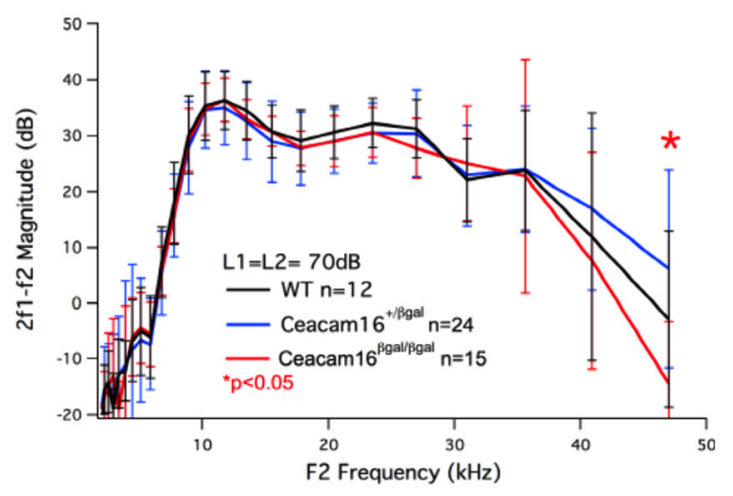

C

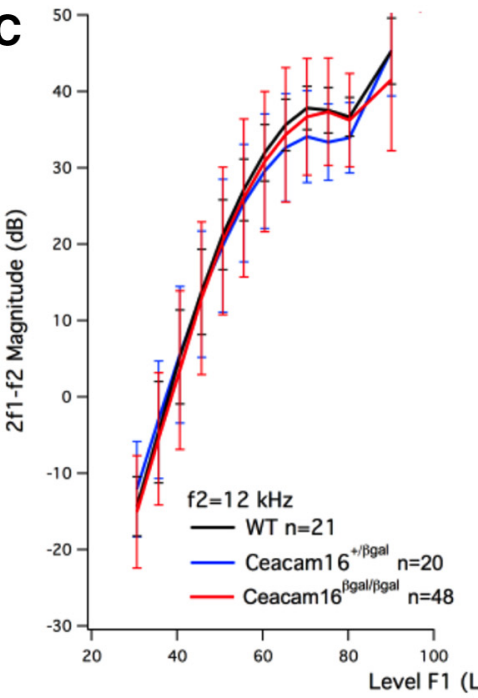

E

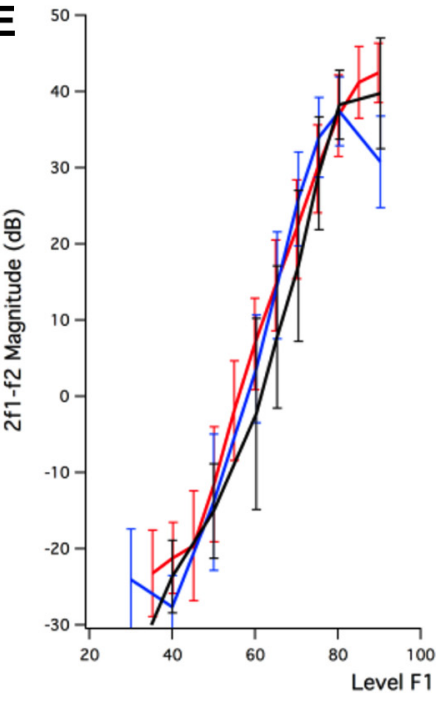

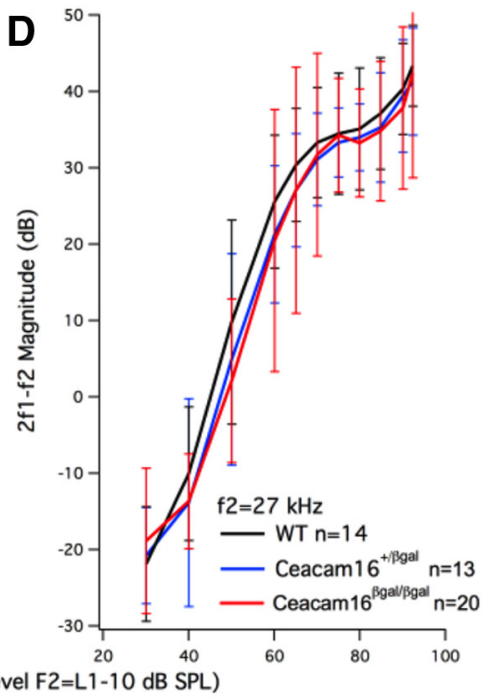

$\mathbf{F}$

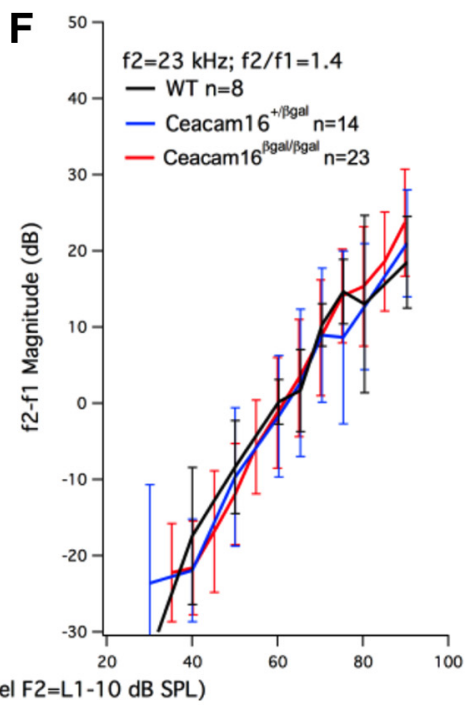

Figure 6. DPOAEs. $A, B$, DP-grams for 2F1-F2 at moderate $(\mathrm{L} 1=50 \mathrm{~dB}$; $\mathrm{L2}-35 \mathrm{~dB}$, bottom) and high ( $\mathrm{L} 1=\mathrm{L2}=70 \mathrm{~dB}$, top) stimulus levels. WT control data are plotted in black, Ceacam $16^{+/ \beta \text { gal }}$ heterozygotes in blue, and Ceacam $16^{\beta \text { gal } / \beta \text { gal }}$ homozygotes in red. The asterisks indicate statistically significant differences between homozygotes and their WT controls. Differences were not significant between heterozygotes and controls. In $A$, the $p$-value at $\mathrm{f} 2=40.9 \mathrm{kHz}$ was 0.0169 ; that for $\mathrm{f} 2=15.5 \mathrm{kHz} 0.0081$, and that for $\mathrm{f} 2=13.5 \mathrm{kHz}$ 0.0309. In $\boldsymbol{B}$, the $p$-value for $\mathrm{f} 2=47 \mathrm{kHz}$ was 0.0444 ). DPOAE input- output functions collected when the level for $F 1$ is $10 \mathrm{~dB}$ higher than that for $F 2$ (F2/F1 $=1.2)$ are plotted in $\boldsymbol{C}-\boldsymbol{F}$. The cubic difference tone is plotted for $\mathrm{F} 2=12 \mathrm{kHz}(\boldsymbol{C})$ and $\mathrm{F} 2=27 \mathrm{kHz}(\boldsymbol{D})$. In addition, DPOAE input- output functions for cubic $(\boldsymbol{E})$ and quadratic $(\boldsymbol{F})$ difference tones are also provided for $\mathrm{F} 2=23 \mathrm{kHz}$ and $\mathrm{F} 2 / \mathrm{F} 1=1.4$.

SFOAE level approached that of the evoking probe tone. In this case, the blue solid lines demonstrate the interaction between the stimulus pressure and that associated with the emission generated in the cochlea. This modulation, however, is largely removed in the presence of the suppressor, as shown by the dashed blue line. The black line shows the SFOAE calculated using vector subtraction. Derived SOAEs plotted in red are observed in the region where the SFOAEs are large and show similar periodicity at $\sim 2.3 \mathrm{kHz}$. Additional results for WT control (black) and Ceacam $16^{\beta \text { gal } / \beta \text { gal }}(\mathrm{red})$ mice are provided in Figure $8 B$, again for a $30 \mathrm{~dB}$ probe stimulus. SFOAEs are unexpectedly much larger in mice lacking CEACAM16 and this difference is underscored in the input-output functions shown in Figure 8C. At all presentation levels, Ceacam $16^{\beta \text { gal } / \beta \text { gal }}$ responses are significantly greater than in WT mice. These functions were obtained at frequencies that generated the largest SFOAEs in the frequency plots. For mice lacking CEACAM16, the stimulus frequency producing the largest SFOAE averaged $21.5 \pm 1.9 \mathrm{kHz}$ (range 14.7-24.6); for
WT mice, the average stimulus frequency was $24.1 \pm 3.5 \mathrm{kHz}$ (range 21.3-32.5). Note that DPOAEs and ABRs did not show a difference between WT and Ceacam $16^{\beta \text { gal/ } / \beta \text { gal }}$ mice in this frequency region.

We also measured TEOAEs at $50 \mathrm{~dB}$ for WT and Ceacam $16^{\beta \text { gal }} \beta$ gal mice. If SFOAEs and TEOAEs are generated by the same mechanism (Wit and Ritsma, 1979; Kemp and Chum, 1980b; Wilson, 1980; Zwicker and Schloth, 1984; Shera and Guinan, 1999), then both of these emission components should show an increase. Data in Figure $8 D$ for mice lacking CEACAM16 (red) indicate larger TEOAEs with respect to control ears, confirming the hypothesis. The constituent probe frequencies for these transients coincided with those that generated the largest SFOAEs. These frequencies ranged between 20 and $25.4 \mathrm{kHz}$.

We also investigated whether DPOAE and ABR thresholds were enhanced in Ceacam $16^{\beta \mathrm{gal} / \beta \text { gal }}$ mice with SOAEs and large SFOAEs/TEOAEs. As for young homozygotes, we found no difference in DPOAE thresholds for F2 $=12 \mathrm{kHz}$, as shown in Table 

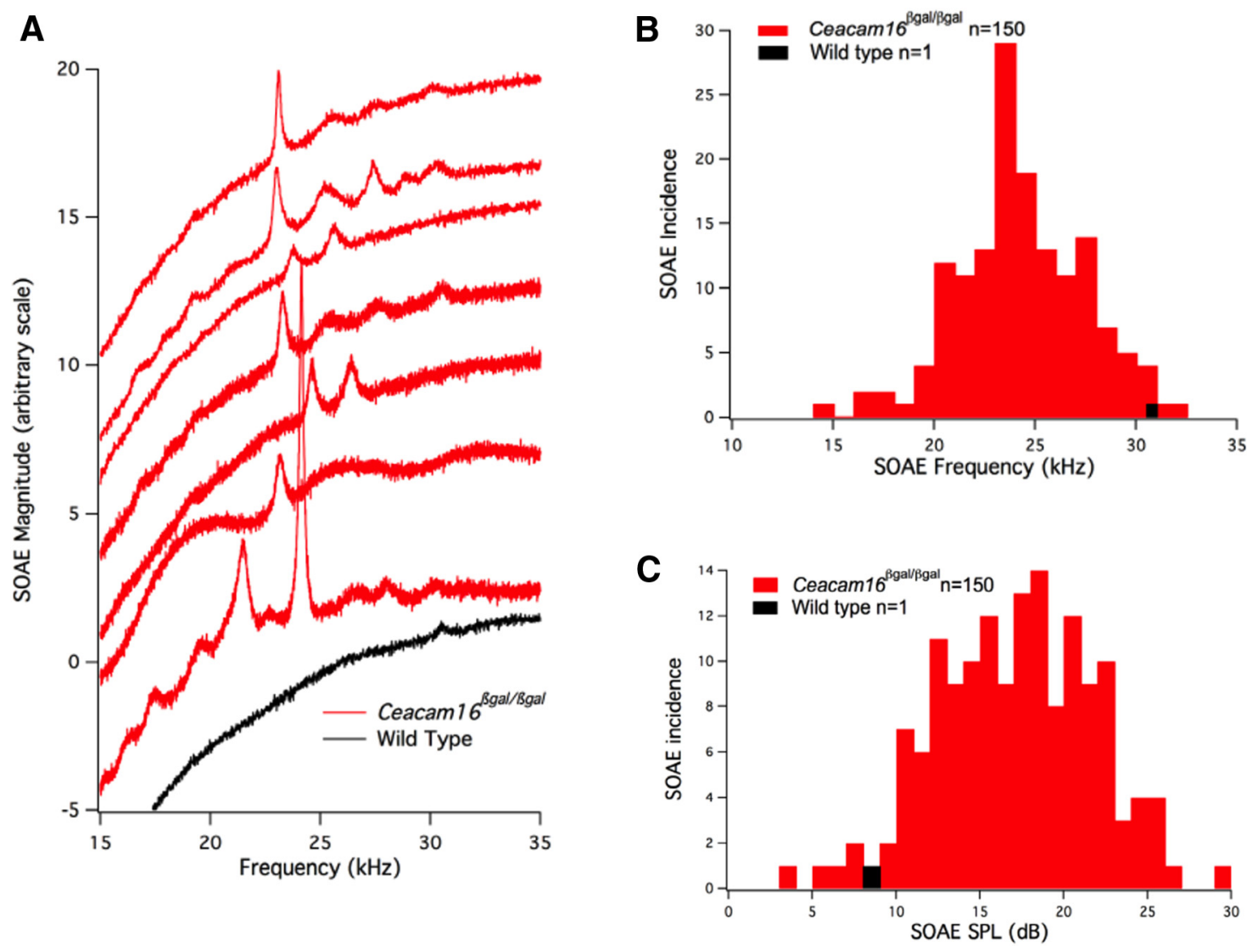

Figure 7. SOAES. SOAEs are plotted in $\boldsymbol{A}$ for Ceacam $16^{\beta}{ }^{\beta \text { gal } /} \beta$ gal homozygotes in red and the only Ceacam $16^{\beta \text { gal }}$ WT mouse with a SOAE in black. The bar graph in $\boldsymbol{B}$ shows the incidence of SOAEs per kHz bin across frequency for all homozygous mice showing this activity, as well as the sole control WT mouse, in black. C, Distribution of SOAEs, which peaks at $\sim 17 \mathrm{~dB}$ for mice lacking CEACAM16. The amplitude of the sole SOAE recorded from a WT mouse is plotted in black.

2. In fact, the average threshold $(0 \mathrm{~dB})$ for Ceacam $16^{\beta \mathrm{gal} / \beta \mathrm{gal}}$ mice was $37.3 \pm 3.9 \mathrm{~dB}$, whereas that for WT was $37.2 \pm 2.7 \mathrm{~dB}$ $(p=0.833)$. Although thresholds for the cubic distortion product generated by F2 $=27 \mathrm{kHz}$ were raised in Ceacam $16^{\beta \mathrm{gal} / \beta \mathrm{gal}}$ mice, the threshold differences were not statistically significant. When we compared SFOAE thresholds, however, the average threshold for homozygotes was $16.0 \pm 6.3 \mathrm{~dB}$ and the WT/heterozygote threshold was $27.8 \pm 7.8 \mathrm{~dB}(p=0.00042)$. A similar improvement in TEOAE thresholds was also observed for Ceacam $16^{\beta \mathrm{gal} /} \beta$ gal mice $(21.6 \pm 6.2 \mathrm{~dB})$ compared with their WT controls $(32.4 \pm 6.1 \mathrm{~dB})$. The more sensitive SFOAE and TEOAE thresholds for Ceacam $16^{\beta \text { gal/ } \beta \text { gal }}$ mice, however, did not translate into better ABR thresholds. The latter were obtained at the same frequency as the SFOAE thresholds and for several nearby frequencies. Even when we chose the best ABR threshold in the vicinity of the SFOAE, Ceacam $16^{\beta \mathrm{gal} / \beta \text { gal }}$ thresholds were $15.5 \pm$ $3.8 \mathrm{~dB}$ and $\mathrm{WT} /$ heterozygous were $17.8 \pm 7.0 \mathrm{~dB}(p=0.97)$. It is, however, acknowledged that ABR thresholds were obtained using $5 \mathrm{~dB}$ changes in stimulus level, so any obvious fine structure may therefore have been missed. In addition, the ABR probably reflects responses generated by a fairly large group of hair cells such that the microstructure is no longer prominent. Because of the complicated nature of emission generation, understanding how these various phenomena are related is not straightforward. Because SFOAE fine structure in mice lacking CEACAM16 likely reflects a synchronization of SOAEs with the probe tone (Burns et al., 1998), it is difficult to interpret interactions between SOAEs and stimulus-related responses.
NLC is normal in Ceacam16 ${ }^{\beta \mathrm{gal} / \boldsymbol{\beta} \mathrm{gal}}$ mice

Mutation in some genes can influence prestin expression. For example, a dominant missense mutation in $\operatorname{Tecta}\left(\right.$ Tecta $\left.^{\mathrm{C} 1509 \mathrm{G} /+}\right)$ produces a shortened TM in heterozygotes such that it couples to only the first row of OHCs and prestin expression is altered (Xia et al., 2010; Liu et al., 2011). This observation suggests that changes in TM anatomy and/or biomechanics could alter prestin expression by affecting $\mathrm{OHC}$ development/elongation. Partial hearing loss can also result in increased prestin expression, as seen after salicylate (Yu et al., 2008) or noise exposure (Chen, 2006; Mazurek et al., 2007; Yu et al., 2008). We therefore measured NLC to assay changes in motor action. Capacitance parameters in mice lacking CEACAM16 were WT like, as shown in Table 3 for the slope factor of the voltage dependence of charge transfer $(\alpha)$, voltage at peak capacitance $\left(V_{\mathrm{pkcm}}\right)$, maximum charge moved $\left(Q_{\max }\right)$, linear capacitance $\left(C_{\text {lin }}\right)$, and charge density $\left(Q_{\max } / C_{\text {lin }}\right)$. This result is consistent with the finding that young Ceacam $16^{\beta \mathrm{gal} / \beta \mathrm{gal}}$ mice have near normal cochlear function, as shown by the in vivo results. A recent report also shows that three different Tecta mutants, all with missense mutations that affect the structure of the TM, have normal prestin expression levels (Legan et al., 2014).

\section{Discussion}

Our previous study (Zheng et al., 2011) announced the discovery of a mutation in Ceacam16 as a cause of a certain type of human hereditary hearing loss and demonstrated that this secreted glycoprotein localizes to the TM and coimmunoprecipitates with 

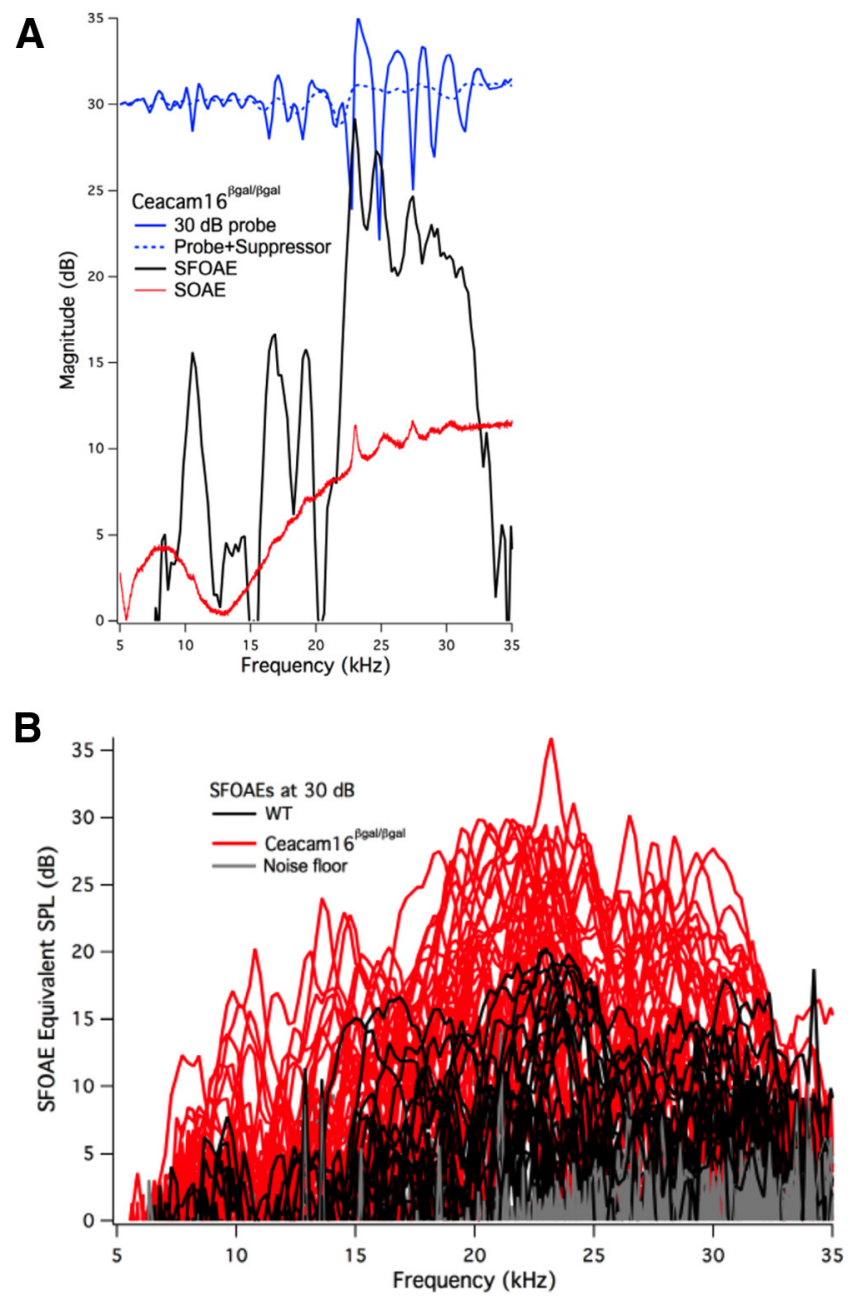

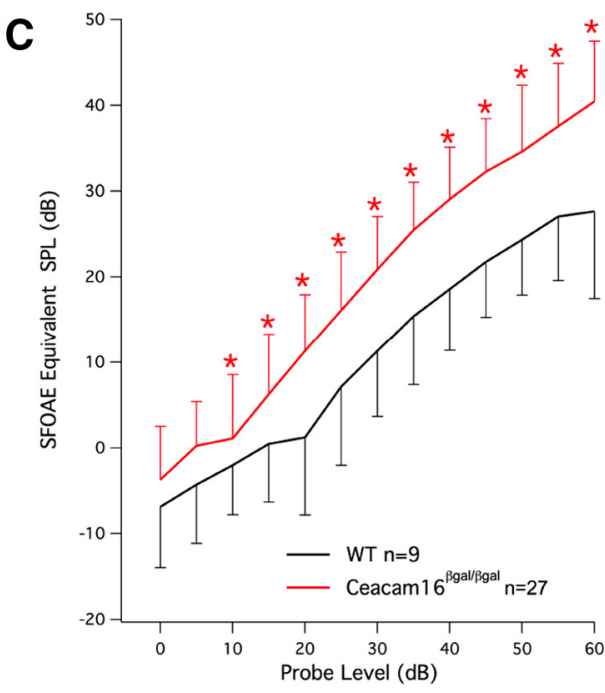

D

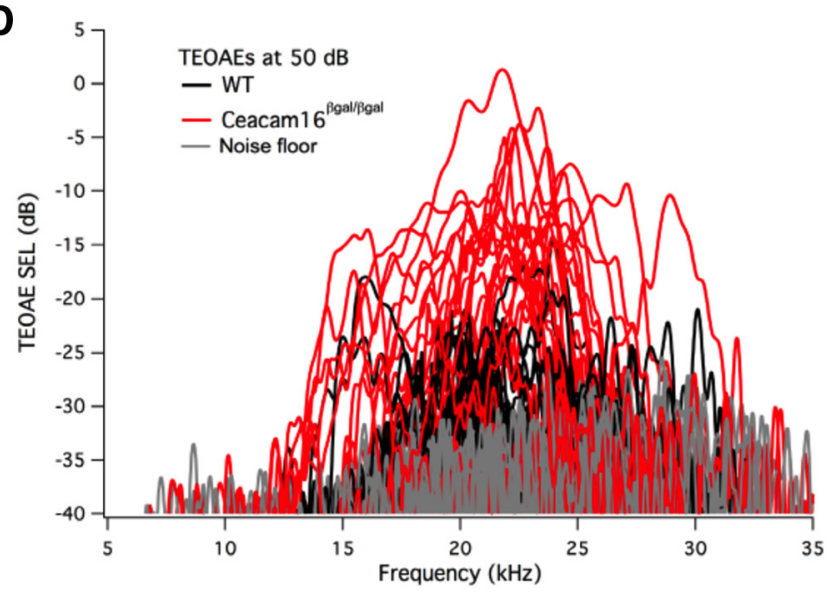

Figure 8. SFOAEs and TEOAEs. Emission magnitude is plotted across frequency in $\boldsymbol{A}$ for an individual mouse lacking CEACAM16. The two curves in blue at the top show the pressure measured in the ear canal without the suppressor (solid line) and during presentation of the suppressor (dashed line), which removes the SFOAE generated in the cochlea and reflected back into the ear canal. The curve in black shows the SFOAE for a $30 \mathrm{~dB}$ probe, whereas the red curve provides the SOAEs. SFOAEs are plotted across frequency for homozygous mice (red) and their WT controls (black) in $B$. The noise floor is indicated in gray. $C$, Input- output functions for the SFOAE producing the largest response at $30 \mathrm{~dB}$. The $p$-values for the input- 0 utput function were 0.0457 at $15 \mathrm{~dB}, 0.0103$ at $20 \mathrm{~dB}$, 0.0205 at $25 \mathrm{~dB}, 0.0055$ at $30 \mathrm{~dB}, 0.0052$ at $35 \mathrm{~dB}, 0.0020$ at $40 \mathrm{~dB}, 0.0009$ at $45 \mathrm{~dB}, 0.0012$ at $50 \mathrm{~dB}, 0.0026$ at $55 \mathrm{~dB}$, and 0.0051 at $60 \mathrm{~dB}$ ). $D$ demonstrates that TE0AEs are larger in Ceacam $16^{\beta \text { gal } / \beta \text { gal }}$ mice. Shown is the sound-equivalent level in $\mathrm{dB}$ for TEOAEs produced at $50 \mathrm{~dB}$ and for a $100 \mu$ s tone pip at the same frequency that produced the largest SFOAE and for which the SFOAE input- output function was collected.

Table 2. 0AE and ABR thresholds for Ceacam $16^{\beta \text { gal } / \beta}$ gal mice lacking CEACAM16 and for WT/heterozygous mice

\begin{tabular}{|c|c|c|c|c|c|}
\hline & SFOAE & TEOAE & $\begin{array}{l}\text { DPOAE } \\
\mathrm{F} 2=12 \\
\mathrm{kHz}\end{array}$ & $\begin{array}{l}\text { DPOAE } \\
\mathrm{F} 2=27 \\
\mathrm{kHz}\end{array}$ & Best ABR \\
\hline C/hot & $27.8 \pm 7.8$ & $32.4 \pm 6.1$ & $37.2 \pm 2.7$ & $46.1 \pm 6.6$ & $17.8 \pm 7.0$ \\
\hline Ceacam $16^{\beta \text { gal } / \beta \text { gal }}$ & $16 \pm 6.3$ & $21.6 \pm 6.2$ & $37.3 \pm 3.9$ & $50 \pm 8.5$ & $15.5 \pm 3.8$ \\
\hline Student's $t$ test & $p=0.0004$ & $p=1.96 \mathrm{E}-05$ & $p=0.8333$ & $p=0.096$ & $p=0.97$ \\
\hline
\end{tabular}

Data are shown as average \pm 1 SD. Although SFOAE and TEOAE thresholds are more sensitive for homozygous Ceacam $16^{\beta \text { gal } / \beta \text { gal }}$ mice, the DPOAE thresholds for $\mathrm{F} 2=12$ and $\mathrm{F} 2=27 \mathrm{kHz}$ are WT like. The ABR threshold for the most sensitive frequency near the SFOAE frequency is also normal.

TECTA. Because these results suggested a role in maintaining the integrity of the TM, Ceacam16-null mutant mice were produced to study the relationship between the structure of the TM and cochlear function. Although TECTA levels are not reduced in the TMs of mice lacking CEACAM16, TECTB levels decrease and evidence is presented indicating that CEACAM16 and TECTB interact. Furthermore, clearly defined striated-sheet matrix never materializes in the Ceacam $16^{\beta \mathrm{gal} / \beta \mathrm{gal}}$ mouse, revealing that CEACAM16 is required for the final maturation of this structural feature. This maturation occurs between P14 and P16, coincident with the onset of hearing. With Ig-variable domains at its $\mathrm{N}$ - and C-termini (Kuespert et al., 2006), CEACAM16 may cross-link TECTB to TECTA, thereby defining the final structure of the matrix. Because CEACAM16 is expressed in older animals after mRNAs for the two tectorins can no longer be detected, its continual production may be required for the long-term maintenance and stability of the matrix within which the collagen fibrils of the TM are embedded.

It is interesting that, over most of the mouse audiogram, sensitivity is normal in young mice lacking CEACAM16; that is, thresholds for both DPOAEs and ABRs are WT like at most frequencies. The fact that NLC is also normal in Ceacam $16^{\beta \mathrm{gal} / \beta \mathrm{gal}}$ mice suggests that all components of the amplifier are working correctly, at least for young Ceacam $16^{\beta \mathrm{gal} / \beta \mathrm{gal}}$ mice on the C57BL/6 background. The WT-like input-output functions for DPOAEs (Fig. 6C,D) also suggest that removal of CEACAM16 does not dramatically alter the contact between Kimura's membrane and the tallest $\mathrm{OHC}$ stereocilia. In addition, Kimura's membrane is not partially detached as it is in Tecta ${ }^{\mathrm{Y} 1870 \mathrm{C}}$ 
Table 3. NLC parameters for Ceacam $16^{\beta \text { gal } / \beta}$ gal mice and their WT controls

\begin{tabular}{|c|c|c|c|c|}
\hline & Average & SD & $n$ & Student's $t$ test \\
\hline \multicolumn{5}{|l|}{ Alpha (mV-1) } \\
\hline WT & 0.029 & 0.003 & 23 & \multirow[t]{2}{*}{$p=0.82$} \\
\hline Ceacam $16^{\beta \mathrm{gal} / \beta \mathrm{gal}}$ & 0.029 & 0.002 & 18 & \\
\hline \multicolumn{5}{|l|}{ Vpkcm (mV) } \\
\hline WT & -82 & 17 & 23 & \multirow[t]{2}{*}{$p=0.90$} \\
\hline Ceacam $16^{\beta \mathrm{gal} / \beta \mathrm{gal}}$ & -82 & 16 & 18 & \\
\hline \multicolumn{5}{|l|}{ Qmax (fC) } \\
\hline WT & 957 & 133 & 23 & \multirow[t]{2}{*}{$p=0.25$} \\
\hline Ceacam $16^{\beta \mathrm{gal} / \beta \mathrm{gal}}$ & 892 & 216 & 18 & \\
\hline \multicolumn{5}{|l|}{ Clin (pF) } \\
\hline WT & 6.8 & 0.7 & 23 & \multirow[t]{2}{*}{$p=0.54$} \\
\hline Ceacam $16^{\beta \mathrm{gal} / \beta \mathrm{gal}}$ & 6.6 & 1.5 & 18 & \\
\hline \multicolumn{5}{|l|}{ Charge density (fC/pF) } \\
\hline WT & 140 & 18 & 23 & \multirow[t]{2}{*}{$p=0.43$} \\
\hline Ceacam $16^{\beta \mathrm{gal} / \beta \mathrm{gal}}$ & 136 & 21 & 18 & \\
\hline
\end{tabular}

Student's $t$ test indicated no statistical difference between these populations.

heterozygotes, in which there is a decrease in DPOAEs and CAPs (Legan et al., 2005). Relative comparisons between cubic and quadratic difference tones (Fig. 6E, F) are also normal, suggesting that the TM attachment crown is secure (Tsuprun and Santi, 2002; Goodyear et al., 2005; Verpy et al., 2011) and that the set point of the $\mathrm{OHC}$ transducer is WT like.

Although not statistically significant, ABR thresholds in Ceacam $16^{\beta \text { gal } / \beta \text { gal }}$ mice show minimally reduced sensitivity at all frequencies, consistent with the idea that spontaneously oscillating ears may be less sensitive than those that do not oscillate. When feedback is excessive and the amplifier becomes oscillatory, gain for external stimuli can decrease (Gold, 1948). In contrast, at the lowest frequency measured, the ABR threshold is statistically different (Student's $t$ test) from controls, similar to the increases in threshold reported by Kammerer et al. (2012). This low-frequency threshold shift may relate to changes in the striated-sheet matrix, which are pronounced in apical regions of the cochlea (Figs. 3, 4). An increase in porosity/decrease in solid fraction of the TM can reduce shear force (Masaki et al., 2010) and may decrease radial fluid flow driven by transverse TM movements (Nowotny and Gummer, 2006). Quantification of the holes observed in the TM indicates, however, that an ABR threshold shift is not observed until the holes account for more than $\sim 20 \%$ of the membrane's cross-sectional area. The observation that $\mathrm{ABR}$ thresholds are near normal for most frequencies coded in the basal $60 \%$ of the cochlea, where Hensen's stripe is absent, is not consistent with the suggestion that IHC bundle deflection is mediated by this TM structure (Masaki et al., 2010). It is conceivable, however, that the presence of Hensen's stripe can influence the phase of IHC excitation (Steele et al., 2009).

In contrast to normal ABRs and DPOAEs, SFOAEs and TEOAEs are larger and SOAEs are dramatically more frequent in Ceacam $16^{\beta \text { gal } / \beta \text { gal }}$ mice, findings that are potentially significant. When discussing these results, it is useful to remember that DPOAEs originate in the region where overlapping excitation patterns associated with the stimulating primaries are large, with the result that DPOAEs can reflect the active process expressed around CF. Some of this energy is distributed in an apically traveling wave to the DPOAE frequency place such that components in the ear canal can be associated with the generation region and/or with the DP place location. In mice, however, DPOAEs generally appear to be dominated by generators in the region of overlap (Heitmann et al., 1997; Banakis et al., 2008; Cheatham et al., 2011). Compared with DPOAEs, SOAEs/SFOAEs/TEOAEs are commonly assumed to form a distinct and separate class of emissions (Shera and Guinan, 1999) and our data are consistent with this taxonomy. It is conceivable, however, that all emissions can be explained by distributed hair cell generators and a single generating mechanism (Kemp and Chum, 1980b; Wilson, 1980; Siegel et al., 2005).

Although the mechanisms of emission generation and back propagation are not completely understood, an explanation for the dichotomy between SOAEs/SFOAEs/TEOAEs and DPOAEs can be sought in anatomical changes seen in the Ceacam16 ${ }^{\beta \mathrm{gal} / \beta \mathrm{gal}}$ mice. The most conspicuous alteration due to loss of CEACAM16 in the basal part of the cochlea is the lack of Hensen's stripe. This finding suggests a possible explanation for the OAE results. An underlying assumption for most discussions on emissions is that an increase in cochlear irregularities could increase the opportunity for reflections and generation of SOAEs (Zweig and Shera, 1995). In addition, modeling suggests that longitudinal coupling within the TM may serve to stabilize cochlear function, thereby enabling high sensitivity (Meaud and Grosh, 2010). A comparative approach in several species of lizards also implies that the TM may influence longitudinal energy distribution, thereby playing an important role in determining emission properties in vertebrate ears (Bergevin et al., 2010). Changes in porosity of the TM can also influence TM traveling waves (Sellon et al., 2014).

Consistent with these ideas, data in this report imply that increases in the SOAE class of emissions in Ceacam $16^{\beta} \mathrm{gal} / \beta \mathrm{gal}$ mice might be related to the loss of Hensen's stripe. Because SOAEs predominate in the octave above $\sim 15 \mathrm{kHz}$, the loss of Hensen's stripe in this same location may underlie their increase, possibly due to changes in the hydrodynamics of subtectorial fluid flow. It is therefore possible that fluid flow within the inner sulcus and subtectorial space changes from a stabilizing energy storage element (de Boer, 1993) to one that may alter the propensity of the cochlea either to produce or retransmit energy in the form of emissions in the absence of Hensen's stripe. Although a static model of shear motion has been entertained since ter Kuile's original descriptions $>100$ years ago (Békésy, 1960), this model does not allow for fluid/structural interactions in the subtectorial space (Nowotny and Gummer, 2006). Shear motion simply results from the translation of transverse BM movements into a differential motion between the TM and reticular lamina, with the result that fluid flow due to these shearing motions stimulates IHCs (Dallos et al., 1972). The potential for more complex interactions requires further characterization of the TM's physical properties to understand how the anatomical changes favor feedback of energy associated with hair cell transduction but without reducing input to IHCs, except for frequencies at the margins of the cochlear frequency/place map. The fact that SOAEs, SFOAEs, and TEOAEs are clustered in the octave between $\sim 16$ and $32 \mathrm{kHz}$ suggests that it is loss of Hensen's stripe, possibly coupled with the holes seen in the TM, that allows for the enhancement of this family of emission components. Because production of numerous SOAEs is wasteful, in that energy is broadcast into the environment with no obvious advantage to hearing, the structure of the TM and the existence of Hensen's stripe may have evolved to suppress these spontaneous activities.

Our data indicate that CEACAM16 is required for striatedsheet matrix formation. Its continual expression may stabilize the noncollagenous TM matrix, the principal proteins of which are only produced during a short window of time early in development (Rau et al., 1999). In the absence of CEACAM16, changes in the striated-sheet matrix, which are dramatic in the apex, may correlate with increased ABR thresholds at the very lowest fre- 
quencies in young Ceacam $16^{\beta \text { gal } / \beta \text { gal }}$ mice. In addition, Hensen's stripe, in the basal regions of the cochlea, may influence hydrodynamic conditions in the subtectorial space that normally suppress SOAEs, SFOAEs, and TEOAEs

It is now generally accepted that OHCs housed within the mammalian organ of Corti produce active mechanical gain to improve both sensitivity and frequency selectivity. Because spontaneous oscillation would compromise these outcomes, the system has evolved to minimize excessive instability. Only a small change in net power generation is required to transform a cochlea with optimized sensitivity and frequency selectivity into an oscillator (Neely and Kim, 1986). Data in this report indicate that changes in the TM due to loss of CEACAM16 alter the coupling between structural elements within the organ of Corti, thereby enhancing selfsustaining oscillations. In this context, SOAEs, SFOAEs, and TEOAEs appear to be sensitive indicators of instability.

\section{References}

Avan P, Büki B, Petit C (2013) Auditory distortions: origins and functions. Physiol Rev 93:1563-1619. CrossRef Medline

Banakis R, Cheatham M, Dallos P, Siegel J (2008) Spontaneous and toneevoked otoacoustic emissions in mice. Assoc Res Otolaryngol Abs, p 66.

Békésy Gv (1960) Experiments in hearing. New York: McGraw-Hill.

Bergevin C, Velenovsky DS, Bonine KE (2010) Tectorial membrane morphological variation: effects upon stimulus frequency otoacoustic emissions. Biophys J 99:1064-1072. CrossRef Medline

Burns EM, Keefe DH, Ling R (1998) Energy reflectance in the ear canal can exceed unity near spontaneous otoacoustic emission frequencies. J Acoust Soc Am 103:462-474. CrossRef Medline

Cheatham MA, Naik K, Siegel J, Dallos P (2011) Intermodulation DPOAEs in mice below and above the eliciting primaries. Assoc Res Otolaryngol Abs, p 33.

Chen GD (2006) Prestin gene expression in the rat cochlea following intense noise exposure. Hear Res 222:54-61. CrossRef Medline

Chen H, Thalmann I, Adams JC, Avraham KB, Copeland NG, Jenkins NA, Beier DR, Corey DP, Thalmann R, Duyk GM (1995) cDNA cloning, tissue distribution, and chromosomal localization of Ocp2, a gene encoding a putative transcription-associated factor predominantly expressed in the auditory organs. Genomics 27:389-398. CrossRef Medline

Cohen-Salmon M, El-Amraoui A, Leibovici M, Petit C (1997) Otogelin: a glycoprotein specific to the acellular membranes of the inner ear. Proc Natl Acad Sci U S A 94:14450-14455. CrossRef Medline

Dallos P, Billone MC, Durrant JD, Wang C, Raynor S (1972) Cochlear inner and outer hair cells: functional differences. Science 177:356-358. CrossRef Medline

de Boer E (1993) The sulcus connection. On a mode of participation of outer hair cells in cochlear mechanics. J Acoust Soc Am 93:2845-2859. CrossRef Medline

Deans MR, Peterson JM, Wong GW (2010) Mammalian Otolin: a multimeric glycoprotein specific to the inner ear that interacts with otoconial matrix protein Otoconin-90 and Cerebellin-1. PLoS One 5:e12765. CrossRef Medline

Frank G, Kössl M (1996) The acoustic two-tone distortions 2f1-f2 and f2-f1 and their possible relation to changes in the operating point of the cochlear amplifier. Hear Res 98:104-115. CrossRef Medline

Gold T (1948) Hearing II-the physical basis of the action of the cochlea. Proc R Soc Lond B 135:492-498. CrossRef

Goodman SS, Fitzpatrick DF, Ellison JC, Jesteadt W, Keefe DH (2009) High-frequency click-evoked otoacoustic emissions and behavioral thresholds in humans. J Acoust Soc Am 125:1014-1032. CrossRef Medline

Goodyear RJ, Marcotti W, Kros CJ, Richardson GP (2005) Development and properties of stereociliary link types in hair cells of the mouse cochlea. J Comp Neurol 485:75-85. CrossRef Medline

Hasko JA, Richardson GP (1988) The ultrastructural organization and properties of the mouse tectorial membrane matrix. Hear Res 35:21-38. CrossRef Medline

Heitmann J, Waldmann B, Schnitzler H, Plinkert PK, Zenner H (1997) Suppression of distortion-product otoacoustic emissions (DPOAE) near 2f1-f2 removes DP-gram fine structure: evidence for a secondary generator. J Acoust Soc Am 103:1527-1531.

Homma K, Duan C, Zheng J, Cheatham MA, Dallos P (2013) The V499G/ $\mathrm{Y} 501 \mathrm{H}$ mutation impairs fast motor kinetics of prestin and has significance for defining functional independence of individual prestin subunits. J Biol Chem 288:2452-2463. CrossRef Medline

Jaramillo F, Markin VS, Hudspeth AJ (1993) Auditory illusions and the single hair cell. Nature 364:527-529. CrossRef Medline

Kammerer R, Rüttiger L, Riesenberg R, Schäuble C, Krupar R, Kamp A, Sunami K, Eisenried A, Hennenberg M, Grunert F, Bress A, Battaglia S, Schrewe H, Knipper M, Schneider MR, Zimmermann W (2012) Loss of mammal-specific tectorial membrane component carcinoembryonic antigen cell adhesion molecule 16 (CEACAM16) leads to hearing impairment at low and high frequencies. J Biol Chem 287:21584-21598. CrossRef Medline

Kane KL, Longo-Guess CM, Gagnon LH, Ding D, Salvi RJ, Johnson KR (2012) Genetic background effects on age-related hearing loss associated with Cdh23 variants in mice. Hear Res 283:80-88. CrossRef Medline

Kemp DT, Chum R (1980a) Properties of the generator of stimulated acoustic emissions. Hear Res 2:213-232. CrossRef Medline

Kemp D, Chum R (1980b) Observations on the generator mechenism of stimulus frequency acoustic emissions-two tone suppression. In: Psychophysical, physiological and behavioral studies in hearing (van den Brink G, Bilsen F, eds), pp 34-42. Delft, The Netherlands: Delft University.

Kemp DT (1978) Stimulated acoustic emissions from the human auditory system. J Acoust Soc Am 64:1386-1391. CrossRef Medline

Kuespert K, Pils S, Hauck CR (2006) CEACAMs: their role in physiology and pathophysiology. Curr Opin Cell Biol 18:565-571. CrossRef Medline

Legan PK, Rau A, Keen JN, Richardson GP (1997) The mouse tectorins: modular matrix proteins of the inner ear homologous to components of the sperm-egg adhesion system. J Biol Chem 272:8791-8801. CrossRef Medline

Legan PK, Lukashkina VA, Goodyear RJ, Kössl M, Russell IJ, Richardson GP (2000) A targeted deletion in alpha-tectorin reveals that the tectorial membrane is required for the gain and timing of cochlear feedback. Neuron 28:273-285. CrossRef Medline

Legan PK, Lukashkina VA, Goodyear RJ, Lukashkin AN, Verhoeven K, Van Camp G, Russell IJ, Richardson GP (2005) A deafness mutation isolates a second role for the tectorial membrane in hearing. Nat Neurosci 8:10351042. CrossRef Medline

Legan PK, Goodyear RJ, Morín M, Mencia A, Pollard H, Olavarrieta L, Korchagina J, Modamio-Hoybjor S, Mayo F, Moreno F, Moreno-Pelayo MA, Richardson GP (2014) Three deaf mice: mouse models for TECTAbased human hereditary deafness reveal domain-specific structural phenotypes in the tectorial membrane. Hum Mol Genet 23:2551-2568. CrossRef Medline

Liu CC, Gao SS, Yuan T, Steele C, Puria S, Oghalai JS (2011) Biophysical mechanisms underlying outer hair cell loss associated with a shortened tectorial membrane. J Assoc Res Otolaryngol 12:577-594. CrossRef Medline

Lukashkin AN, Russell IJ (2002) Modifications of a single saturating nonlinearity account for post-onset changes in $2 \mathrm{f} 1-\mathrm{f} 2$ distortion product otoacoustic emission. J Acoust Soc Am 112:1561-1568. CrossRef Medline

Lukashkin AN, Legan PK, Weddell TD, Lukashkina VA, Goodyear RJ, Welstead LJ, Petit C, Russell IJ, Richardson GP (2012) A mouse model for human deafness DFNB22 reveals that hearing impairment is due to a loss of inner hair cell stimulation. Proc Natl Acad Sci U S A 109:19351-19356. CrossRef Medline

Malumbres M, Mangues R, Ferrer N, Lu S, Pellicer A (1997) Isolation of high molecular weight DNA for reliable genotyping of transgenic mice. Biotechniques 22:1114-1119. Medline

Manley GA, Kirk DL, Köppl C, Yates GK (2001) In vivo evidence for a cochlear amplifier in the hair-cell bundle of lizards. Proc Natl Acad Sci U S A 98:2826-2831. CrossRef Medline

Masaki K, Ghaffari R, Gu JW, Richardson GP, Freeman DM, Aranyosi AJ (2010) Tectorial membrane material properties in Tecta $(\mathrm{Y})(1870 \mathrm{C} /+)$ heterozygous mice. Biophys J 99:3274-3281. CrossRef Medline

Mazurek B, Haupt H, Amarjargal N, Yarin YM, Machulik A, Gross J (2007) Up-regulation of prestin mRNA expression in the organs of Corti of guinea pigs and rats following unilateral impulse noise exposure. Hear Res 231:73-83. CrossRef Medline

Meaud J, Grosh K (2010) The effect of tectorial membrane and basilar 
membrane longitudinal coupling in cochlear mechanics. J Acoust Soc Am 127:1411-1421. CrossRef Medline

Mom T, Bonfils P, Gilain L, Avan P (2001) Origin of cubic difference tones generated by high-intensity stimuli: effect of ischemia and auditory fatigue on the gerbil cochlea. J Acoust Soc Am 110:1477-1488. CrossRef Medline

Müller M, von Hünerbein K, Hoidis S, Smolders JW (2005) A physiological place-frequency map of the cochlea in the CBA/J mouse. Hear Res 202: 63-73. CrossRef Medline

Neely ST, Liu Z (1994) EMAV: Otoacoustic emission averager. Omaha, NE: Technical Memo No 17, Boy's Town National Research Hospital.

Neely ST, Kim DO (1986) A model for active elements in cochlear biomechanics. J Acoust Soc Am 79:1472-1480. CrossRef Medline

Neely ST, Stevenson R (1992) SysRes. Omaha, NE: Tech Memo No. 1, BoysTown National Research Hospital NE.

Nowotny M, Gummer AW (2006) Nanomechanics of the subtectorial space caused by electromechanics of cochlear outer hair cells. Proc Natl Acad Sci U S A 103:2120-2125. CrossRef Medline

Ostermeier GC, Wiles MV, Farley JS, Taft RA (2008) Conserving, distributing and managing genetically modified mouse lines by sperm cryopreservation. PLoS One 3:e2792. CrossRef Medline

Papaioannou V, Johnson R (1993) Production of chimeras and genetically defined offspring from targeted ES cells. In: Gene targeting: a practical approach (Joyner AL, ed), pp 107-146. Oxford: IRL.

Pettitt SJ, Liang Q, Rairdan XY, Moran JL, Prosser HM, Beier DR, Lloyd KC, Bradley A, Skarnes WC (2009) Agouti C57BL/6N embryonic stem cells for mouse genetic resources. Nat Methods 6:493-495. CrossRef Medline

Rau A, Legan PK, Richardson GP (1999) Tectorin mRNA expression is spatially and temporally restricted during mouse inner ear development. J Comp Neurol 405:271-280. CrossRef Medline

Richardson GP, Russell IJ, Duance VC, Bailey AJ (1987) Polypeptide composition of the mammalian tectorial membrane. Hear Res 25:45-60. CrossRef Medline

Richardson GP, Lukashkin AN, Russell IJ (2008) The tectorial membrane: one slice of a complex cochlear sandwich. Curr Opin Otolaryngol Head Neck Surg 16:458-464. CrossRef Medline

Richardson GP, de Monvel JB, Petit C (2011) How the genetics of deafness illuminates auditory physiology. Annu Rev Physiol 73:311-334. CrossRef Medline

Russell IJ, Kössl M (1992) Sensory transduction and frequency selectivity in the basal turn of the guinea-pig cochlea. Philos Trans R Soc Lond B Biol Sci 336:317-324. CrossRef Medline

Santos-Sacchi J, Kakehata S, Takahashi S (1998) Effects of membrane potential on the voltage dependence of motility-related charge in outer hair cells of the guinea-pig. J Physiol 510:225-235. CrossRef Medline

Sellon JB, Ghaffari R, Farrahi S, Richardson GP, Freeman DM (2014) Porosity controls spread of excitation in tectorial membrane traveling waves. Biophys J 106:1406-1413. CrossRef Medline

Shera CA (2003) Mammalian spontaneous otoacoustic emissions are amplitude-stabilized cochlear standing waves. J Acoust Soc Am 114:244262. CrossRef Medline

Shera CA, Guinan JJ Jr (1999) Evoked otoacoustic emissions arise by two fundamentally different mechanisms: a taxonomy for mammalian OAEs. J Acoust Soc Am 105:782-798. CrossRef Medline

Shera CA, Guinan JJ Jr (2003) Stimulus-frequency-emission group delay: a test of coherent reflection filtering and a window on cochlear tuning. J Acoust Soc Am 113:2762-2772. CrossRef Medline

Siegel JH (2006) The biophysical origin of otoacoustic emissions. In: Auditory mechanisms: process and models (Nuttall AF, Ren T, Gillespie P, Grosh C, de Boer E, eds), pp 361-368. Portland, OR: World Scientific.

Siegel JH (2007) Calibrating otoacoustic emissions probes. In: Otoacoustic emissions: clinical applications (Robinette MS, Glattke TJ, eds). New York: Thieme.

Siegel JH, Cerka AJ, Recio-Spinoso A, Temchin AN, van Dijk P, Ruggero MA
(2005) Delays of stimulus-frequency otoacoustic emissions and cochlear vibrations contradict the theory of coherent reflection filtering. J Acoust Soc Am 118:2434-2443. CrossRef Medline

Siegel JH, Charaziak K, Cheatham MA (2011) Transient- and tone-evoked otoacoustic emissions in three species. In: What fire is in mine ears: progress in auditory biomechanics, XIth International Mechanics of Hearing Workshop (Shera CA, Olson ES, eds), pp 307-314. Melville, NY: American Institute of Physics.

Steele CR, Boutet de Monvel J, Puria S (2009) A multiscale model of the organ of Corti. Journal of Mechanics of Materials and Structures 4:755778. CrossRef Medline

Talmadge CL, Long GR, Murphy WJ, Tubis A (1993) New off-line method for detecting spontaneous otoacoustic emissions in human subjects. Hear Res 71:170-182. CrossRef Medline

Testa G, Schaft J, van der Hoeven F, Glaser S, Anastassiadis K, Zhang Y, Hermann T, Stremmel W, Stewart AF (2004) A reliable lacZ expression reporter cassette for multipurpose, knockout-first alleles. Genesis 38:151158. CrossRef Medline

Thalmann I, Thallinger G, Comegys TH, Thalmann R (1986) Collagen-the predominant protein of the tectorial membrane. ORL J Otorhinolaryngol Relat Spec 48:107-115. CrossRef Medline

Tsuprun V, Santi P (2002) Structure of outer hair cell stereocilia side and attachment links in the chinchilla cochlea. J Histochem Cytochem 50: 493-502. CrossRef Medline

Verpy E, Leibovici M, Michalski N, Goodyear RJ, Houdon C, Weil D, Richardson GP, Petit C (2011) Stereocilin connects outer hair cell stereocilia to one another and to the tectorial membrane. J Comp Neurol 519:194_ 210. CrossRef Medline

Wilson JP (1980) Evidence for a cochlear origin for acoustic re-emissions, threshold fine-structure and tonal tinnitus. Hear Res 2:233-252. CrossRef Medline

Wit HP, Ritsma RJ (1979) Stimulated acoustic emissions from the human ear. J Acoust Soc Am 66:911-913.

Xia A, Gao SS, Yuan T, Osborn A, Bress A, Pfister M, Maricich SM, Pereira FA, Oghalai JS (2010) Deficient forward transduction and enhanced reverse transduction in the alpha tectorin C1509G human hearing loss mutation. Disease Models and Mechanisms 3:209-223. CrossRef Medline

Yang T, Pfister M, Blin N, Zenner HP, Pusch CM, Smith RJ (2005) Genetic heterogeneity of deafness phenotypes linked to DFNA4. Am J Med Genet A 139:9-12. CrossRef Medline

Yariz KO, Duman D, Seco CZ, Dallman J, Huang M, Peters TA, Sirmaci A, Lu N, Schraders M, Skromne I, Oostrik J, Diaz-Horta O, Young JI, TokgozYilmaz S, Konukseven O, Shahin H, Hetterschijt L, Kanaan M, Oonk AM, Edwards YJ, et al. (2012) Mutations in OTOGL, encoding the inner ear protein otogelin-like, cause moderate sensorineural hearing loss. Am J Hum Genet 91:872-882. CrossRef Medline

Yu N, Zhu ML, Johnson B, Liu YP, Jones RO, Zhao HB (2008) Prestin up-regulation in chronic salicylate (aspirin) administration: an implication of functional dependence of prestin expression. Cell Mol Life Sci 65:2407-2418. CrossRef Medline

Zheng J, Miller KK, Yang T, Hildebrand MS, Shearer AE, DeLuca AP, Scheetz TE, Drummond J, Scherer SE, Legan PK, Goodyear RJ, Richardson GP, Cheatham MA, Smith RJ, Dallos P (2011) Carcinoembryonic antigenrelated cell adhesion molecule 16 interacts with alpha-tectorin and is mutated in autosomal dominant hearing loss (DFNA4). Proc Natl Acad Sci U S A 108:4218-4223. CrossRef Medline

Zid M, Drouin G (2013) Gene conversions are under purifying selection in the carcinoembryonic antigen immunoglobulin gene families of primates. Genomics 102:301-309. CrossRef Medline

Zweig G, Shera CA (1995) The origin of periodicity in the spectrum of evoked otoacoustic emissions. J Acoust Soc Am 98:2018-2047. CrossRef Medline

Zwicker E, Schloth E (1984) Interrelation of different oto-acoustic emissions. J Acoust Soc Am 75:1148-1154. CrossRef Medline 